\title{
An experimental investigation to characterise soil macroporosity under different land use and land covers of northeast India
}

\author{
Sangeeta Shougrakpam ${ }^{1}$, Rupak Sarkar ${ }^{2}$ and Subashisa Dutta ${ }^{1, *}$ \\ ${ }^{1}$ Department of Civil Engineering, Indian Institute of Technology Guwahati, \\ North Guwahati, Assam 781 039, India. \\ ${ }^{2}$ Faculty of Technology, Uttar Banga Krishi Viswavidyalaya (UBKV), Pundibari, \\ Cooch Behar 736 165, West Bengal, India. \\ *e-mail: subashisa@iitg.ernet.in
}

\begin{abstract}
Saturated macropore flow is the dominant hydrological process in tropical and subtropical hilly watersheds of northeast India. The process of infiltration into saturated macroporous soils is primarily controlled by size, network, density, connectivity, saturation of surrounding soil matrix, and depthwise distribution of macropores. To understand the effects of local land use, land cover and management practices on soil macroporosity, colour dye infiltration experiments were conducted with ten soil columns $(25 \times 25 \times 50 \mathrm{~cm})$ collected from different watersheds of the region under similar soil and agro-climatic zones. The sampling sites included two undisturbed forested hillslopes, two conventionally cultivated paddy fields, two forest lands abandoned after Jhum cultivation, and two paddy fields, one pineapple plot and one banana plot presently under active cultivation stage of the Jhum cycle. Digital image analyses of the obtained dye patterns showed that the infiltration patterns differed significantly for different sites with varying land use, land cover, and cultivation practices. Undisturbed forest soils showed high degree of soil macroporosity throughout the soil profile, paddy fields revealed sealing of macropores at the topsoil due to hard pan formation, and Jhum cultivated plots showed disconnected subsoil macropores. The important parameters related to soil macropores such as maximum and average size of macropores, number of active macropores, and depthwise distribution of macropores were estimated to characterise the soil macroporosity for the sites. These experimentally derived quantitative data of soil macroporosity can have wide range of applications in the region such as water quality monitoring and groundwater pollution assessment due to preferential leaching of solutes and pesticides, study of soil structural properties and infiltration behaviour of soils, investigation of flash floods in rivers, and hydrological modelling of the watersheds.
\end{abstract}

\section{Introduction}

In northeast India, the landscapes are mainly characterised by the vegetated hillslopes and floodplains of river Brahmaputra and its tributaries. The hydrological modelling of these watersheds is a challenging task because of the presence of active macropore network in the subsoil of the vegetated hillslopes (Sarkar et al 2008) and the occurrence of frequent extreme rainfall events $(>100 \mathrm{~mm} / \mathrm{h}$ ) during the rainy seasons (Soja and Starkel 2007). The adoptions of different land uses are also known to have significant impact on the rainfall-runoff responses from these watersheds ( $\mathrm{Yu}$ et al 2003; Zhao et al 2004; Alansi et al 2009). However, due to the lack of experimental data or reliable

Keywords. Hillslope; land use and land cover; infiltration; macropores; dye pattern analysis; experiments; hydrology; instruments and techniques. 
empirical models for these watersheds, little is known about infiltration behaviour, macropore connectivity, subsurface flow pattern through soil macropores, and the resulting runoff response of the watersheds subjected to different land use, land cover, and cultivation practices (Sarkar and Dutta 2009). Therefore, as a prerequisite to develop any rainfall-runoff model it is essential to characterise both surface and subsurface flow behaviour with good understanding of the dominant hydrological processes of the region (Uchida et al 2005).

The land cover of most of the watersheds is dominated by densely vegetated hillslopes with highly interconnected network of macropores in the topsoil (Sarkar et al 2008). These hillslopes have a significant impact on the hydrology of the region. Irrigated agriculture is mainly practiced in plane lands which are typically surrounded by hillslopes. Paddy (Oryza sativa) is the most common land use for these agricultural lands. The dominant soil formations and infiltration behaviour of paddy fields lead to a unique hydrological regime of the watersheds dominated by paddy agriculture (Paulo et al 1995; Kar and Das 2000; Chen and Liu 2002). A good understanding of the infiltration behaviour of the paddy fields is important to assess their impact on the hydrology of these watersheds (Mishra et al 2008).

In northeast India, Jhum cultivation has gained popularity as an organic multi-crop farming system as it is more economic than the other alternative forms of agriculture which require more investment and maintenance. Shifting cultivation or rotational 'bush and fallow agriculture' is popularly known as Jhum cultivation in northeast India. This is an ancient practice of 'slash-and-burn agriculture', particularly in the wet tropical forests and hillslopes of the region. The method involves clearing a patch of forest land, but retaining useful trees and plants, cultivating the land for 2-3 years and then abandoning it for 10-20 years to allow the natural forest to grow back and the soil to regain its fertility in terms of essential nutrients for crop production. The rotational sequence of these events is called the Jhum cycle. Ecological sustainability requires a minimum fallow period of at least 10 years (Goswami 1980; Sanchez and Hailu 1996). But, due to increasing demand of cultivable lands and timber the conventional Jhum cycle has been shortened to about 5-6 years. Consequently, this traditional form of agricultural practice has resulted in serious environmental problems such as loss of forest cover, erosion of topsoil, desertification, and decline in soil fertility in the region (Stracey 1967). Shifting/swidden agriculture and timber removal are cited commonly as the main reason of soil and nutrient loss and other hydrological impacts such as river/reservoir sedimentation, flood, and drought (Sharma 1992; Tuan 1993). Gafur et al (2003) reported considerable losses of soil and nutrients with runoff water from small watersheds under shifting cultivation (Jhum) in Chittagong hill tracts of Bangladesh. The role of forest vegetation in watershed hydrology and the effect of deforestation on hydrological response have been widely reported (Edwards 1977; Bosch and Hewlett 1982; Sastry and Narayanan 1986; Lal 1987; Bruijnzeel 1990; Calder 2000). Land management practices have considerable effect on soil structure and consequently on overall sustainability of the agricultural production system (Pagliai et al 2004). Ziegler et al (2004) reported that human activity in even a very small fraction (less than $1 \%$ ) of the watershed area reduced infiltration rate considerably and resulted in disproportionate overland flow generation during typical rainfall events. They also reported that the reduction in saturated hydraulic conductivity $\left(K_{s}\right)$ was maximum in the recently abandoned fields. The $K_{s}$ of the top-soil layer increased as the secondary vegetation grew in the abandoned field. But the recovery time of $K_{s}$ for lower soil layers was considerably more (15-25 years) and lingered long after the vegetation evolved to mature forests.

The presence of macropores generally leads to heterogeneity of flow within the soil (Ligon et al 1977; Germann 1981). The size of macropores and their connectivity, which may change within a few centimeters, can influence the infiltration behaviour of soil (Beven and Germann 1982). In forested hilly watersheds, with high intensity rainfall events, the spatial and temporal variations of active macropore flow network primarily governs both surface and subsurface runoff generation processes (McDonnell 1990; Smettem et al 1991; Návar et al 1995; Bronstert 1999; Sidle et al 2000). A number of studies have been conducted towards understanding the nature of flow through soil macropores. Specific aspects of macropore flow dynamics such as the effects of tillage, pore continuity, soil surface coverage, rainfall intensity, and antecedent water content were addressed (Andreini and Steenhuis 1990; Shipitalo et al 1990; Edwards et al 1993; Shipitalo and Edwards 1996). To better understand the macropore flow behaviour practical in situ experimental investigation has been suggested by many researchers (Hoogmoed and Bouma 1980; Weiler 2001, 2005; Ticehurst et al 2003; Rajot et al 2004).

Dye staining and digital image processing can be a useful technique to study the preferential infiltration behaviour in soils with macropores (Bouma and Dekker 1978; Bouma and Wosten 1979; Bouma et al 1979; Omoti and Wild 1979; 
van Stiphout et al 1987; Ghodrati and Jury 1990; Flury et al 1994; Natsch et al 1996; Forrer et al 1999; Perillo et al 1999; Weiler 2001; Weiler and Naef 2003; Morris and Mooney 2004; Wang et al 2006; Alaoui and Goetz 2008; Anderson et al 2008). This technique can be a reliable indicator of active macropore flow pathways which can easily be detected and quantified from laboratory experiments conducted with undisturbed soil columns collected from the field. As these continuous macropore pathways are essentially related to preferential flow, the degree of macroporosity obtained can be used effectively as a descriptive tool for comparing the effects of soil management on soil structure (Cattle et al 1994). Several studies have suggested that, in addition to surface connected macropores, subsurface macropores can also play an important role in the preferential flow of water and solutes (Quisenberry and Phillips 1976; Li and Ghodrati 1997). van Stiphout et al (1987) used dye tracer and soil moisture measurements to study infiltration behaviour in macroporous soil at the plot scale with both dry and wet initial soil moisture conditions. Droogers et al (1998) used dye staining technique with subsequent digital image processing to quantify parameters for describing macroporosity in soils under different management practices. They reported that the number of pores, the average area per pore, and the pore-shape were the most appropriate parameters to describe soil macroporosity. To understand the specific processes involved in macropore flow Ghodrati et al (1999) conducted a dye tracer experiment with a Split Macropore Column (SMC) in the laboratory. With a single macropore in a cylindrical soil sample, the effect of the physical parameters such as size, density, and continuity of macropores were investigated and the results suggested that the macropore flow was mostly influenced by matrix-macropore size ratio than by the macropore size alone. Öhrström et al (2002) carried out a field investigation in semiarid Tunisia to investigate spatial variability of preferential pathways in both hillslope and plot scales. Analysis of dye distribution patterns indicated that the preferential pathways were randomly distributed. The results also showed that the physiographic features of the watersheds such as nose, slope, and hollow significantly influenced the dye infiltration patterns. Wahl et al (2003) conducted dye tracer experiments on confined irrigation plots and the stained and unstained areas at different depths were analysed using GIS-software to study the infiltration capacity and macroporosity of soil under different tillage systems.

In northeast India, hydrologists often find it difficult to develop physically based hydrological models due to lack of detailed hydrological information (Sarkar and Dutta 2009). Therefore, the need of process based hydrological studies in the region has been stressed (Negi 2001). The World Bank (2007) has also pointed out that significant data limitations have restricted the analyses in different fields related to water resources, environmental pollution, and forest/biodiversity of northeast India. Saturated macropore flow is the dominant hydrological process in the vegetated hilly watersheds. In order to develop a better understanding on infiltration and water movement through soil, we need to quantify soil macroporosity and trace the dominating flow paths within continuous soil macropores to elucidate the underlying flow mechanism. Especially, in Jhum cultivated watersheds little is known about the change in soil macroporosity due to Jhum cultivation and the issue of hydrological recovery after the land is abandoned. This paper aims to understand the flow behaviour in active macropore structures of saturated undisturbed soil columns collected from undisturbed forests, conventional crop fields, and Jhum cultivated lands of the region. Dye tracing experiments and subsequent digital image processing techniques were used to estimate the number of macropores, average number of macropores, maximum size of macropores, and volume density in terms of stained path width with depth as an explanatory variable. These parameters can be used to compare, evaluate, and quantify the differences in soil macroporosity under different land use, land cover, and crop management practices. The quantitative information collected about the macropore flow patterns may be used in different fields of science and engineering applications such as ground water pollution and water quality modelling due to leaching of solutes, pesticides, and nitrates in macroporous soils (Jarvis et al 1991; Flury 1996; Jarvis 1998; Larsson and Jarvis 1999, 2000; Mooney and Morris 2008), study of soil structural properties and infiltration behaviour (Olsen and Børresen 1997; Buttle and McDonald 2000), identification of lateral macropore flow responsible for flash floods (Anderson et al 2008; Elçi and Molz 2009), and hydrological investigations of rainfall-runoff processes. Weiler (2005) developed a hydrological model based on the data collected from similar experimental investigations. More recently such experimental data have been used to define the average size of soil macropores to successfully model lateral preferential flow in a hillslope of northeast India (Sarkar and Dutta 2009). Borah and Kalita (1999) reported that the addition of a macropore flow component improved the prediction capability of a solute leaching model (LEACHM). They also suggested that the use of 

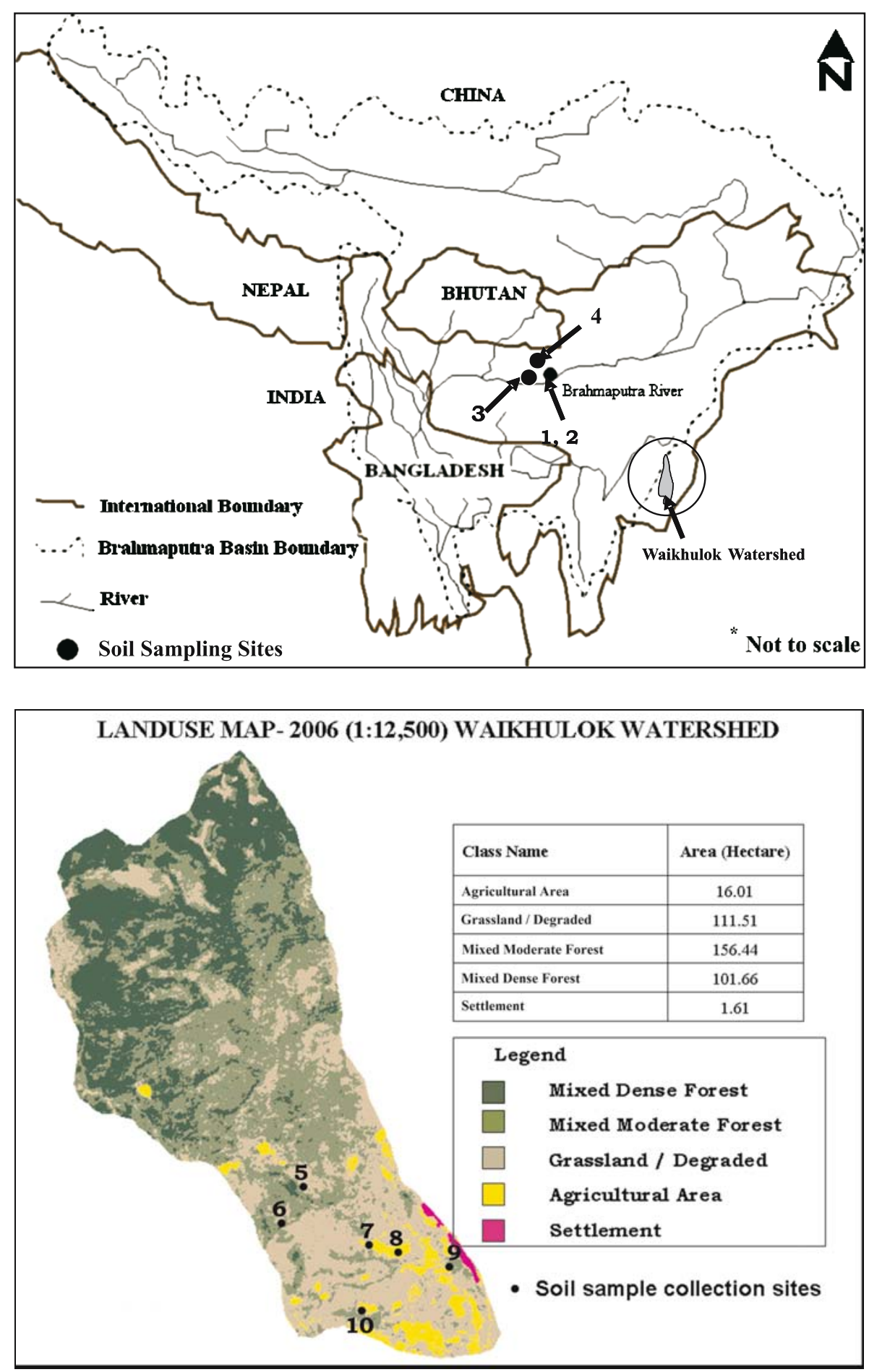

Figure 1. Locations of the soil sampling sites in the study area.

more site specific macroporosity data is likely to further improve the model predictions.

\section{Description of soil sampling sites}

To quantify the effects of different land use and cultivation practices on soil macroporosity, soil columns were collected from different locations in northeast India with distinct land uses (figure 1). A total number of 10 soil columns, each having dimension of $25 \times 25 \times 50 \mathrm{~cm}$, were collected from four watersheds, namely, Amingaon, Avayapur, Rudreswar Gaon, and Waikhulok. Each column contained a total volume of $31250 \mathrm{~cm}^{3}$ of soil, which we considered a reasonable volume to capture the local scale macropore distribution in natural field condition as small diameter macropores $(1-4 \mathrm{~mm})$ 
Table 1. Description of the locations of undisturbed soil sample collection.

\begin{tabular}{|c|c|c|c|}
\hline $\begin{array}{l}\text { Soil } \\
\text { column no. }\end{array}$ & $\begin{array}{l}\text { Watershed name and } \\
\text { geographic location }\end{array}$ & Elevation $(\mathrm{m})$ & Land use type \\
\hline 1,2 & $\begin{array}{l}\text { Name: Amingaon } \\
\text { Latitude: } 26^{\circ} 12^{\prime} \mathrm{N} \\
\text { Longitude: } 91^{\circ} 42^{\prime} \mathrm{E}\end{array}$ & 55 & Undisturbed natural forested hillslopes \\
\hline 3 & $\begin{array}{l}\text { Name: Avayapur } \\
\text { Latitude: } 26^{\circ} 12^{\prime} \mathrm{N} \\
\text { Longitude: } 90^{\circ} 43^{\prime} \mathrm{E}\end{array}$ & 48 & $\begin{array}{l}\text { Recently harvested paddy field in plain land } \\
\text { without Jhum cultivation }\end{array}$ \\
\hline 4 & $\begin{array}{l}\text { Name: Rudreswar Gaon } \\
\text { Latitude: } 26^{\circ} 13^{\prime} \mathrm{N} \\
\text { Longitude: } 90^{\circ} 44^{\prime} \mathrm{E}\end{array}$ & 50 & $\begin{array}{l}\text { Recently harvested paddy field in plain land } \\
\text { without Jhum cultivation }\end{array}$ \\
\hline 5,6 & $\begin{array}{l}\text { Name: Waikhulok Watershed } \\
\text { Latitude: } 24^{\circ} 82^{\prime} \mathrm{N} \text { to } 24^{\circ} 84^{\prime} \mathrm{N} \\
\text { Longitude: } 93^{\circ} 77^{\prime} \mathrm{E} \text { to } 93^{\circ} 79^{\prime} \mathrm{N}\end{array}$ & $900-1500$ & Forest land abandoned after Jhum cultivation \\
\hline 7,8 & - do- & - do- & $\begin{array}{l}\text { Recently harvested paddy fields under Jhum } \\
\text { cultivation }\end{array}$ \\
\hline 9 & - do- & - do- & Pineapple under Jhum cultivation \\
\hline 10 & - do- & - do- & Banana plantation under Jhum cultivation \\
\hline
\end{tabular}

Table 2. Soil textural properties of the samples collected from the study area.

\begin{tabular}{lccccc}
\hline $\begin{array}{l}\text { Soil } \\
\text { columns }\end{array}$ & $\begin{array}{c}\text { Average } \\
\text { sand (\%) }\end{array}$ & $\begin{array}{c}\text { Average } \\
\text { silt }(\%)\end{array}$ & $\begin{array}{c}\text { Average } \\
\text { clay }(\%)\end{array}$ & $\begin{array}{c}\text { Average } \\
\text { porosity }\end{array}$ & $\begin{array}{c}\text { Average bulk } \\
\text { density (g/cc) }\end{array}$ \\
\hline 1 (Natural forest) & 22.03 & 69.50 & 8.47 & 0.56 & 1.21 \\
2 (Natural forest) & 28.75 & 62.43 & 8.82 & 0.52 & 1.24 \\
3 (Conventional paddy) & 1.44 & 90.70 & 7.86 & 0.45 & 1.74 \\
4 (Conventional paddy) & 0.08 & 78.92 & 21.00 & 0.44 & 1.76 \\
5 (Jhum forest) & 51.50 & 34.00 & 14.50 & 0.48 & 1.38 \\
6 (Jhum forest) & 49.54 & 36.23 & 14.23 & 0.51 & 1.33 \\
7 (Jhum paddy) & 60.50 & 24.10 & 15.40 & 0.47 & 1.46 \\
8 (Jhum paddy) & 53.00 & 38.90 & 18.10 & 0.52 & 1.51 \\
9 (Jhum pineapple) & 57.00 & 25.70 & 17.30 & 0.49 & 1.43 \\
10 (Jhum banana) & 53.00 & 25.50 & 21.50 & 0.44 & 1.39 \\
\hline
\end{tabular}

developed by plant roots dominated the soil profile (de Rooij and Stagnitti 2000; Mooney and Morris 2008). Table 1 shows the land use types of different soil sampling sites. The sampling sites were required to be selected to represent the most common land use and land covers of northeast India. As it was difficult to have all the representative land types within a single watershed, the sampling sites were selected from different watersheds of the region. However, they all belong to the same soil and agro-climatic zones with similar subsurface geologic formations. Study of soil maps and satellite imageries as well as information from soil conservation departments, agriculture departments, and knowledge of local people helped in proper selection of the sampling sites. Such distant sampling also ensured that the undisturbed forest and paddy field soil columns were collected from sites that were never affected by
Jhum cultivation. As the soil sampling locations were widely distributed and they were subjected to different land use and cultivation methods, some spatial variations in soil textural properties and bulk densities were evident (table 2). This is a limitation of comparing the infiltration patterns obtained from different soil samples. However, the variations in macropore flow patterns can be attributed mainly to the different land treatments and management practices such as tillage, Jhum cultivation, local vegetation, and minor differences in soil textures. Visual observations of all the soil samples showed that there were very few structural voids (cracks and fissures) and the preferential pathways were mainly formed by plant roots. Thus, macropore flow patterns could be related to the differences in land use, land cover, and cultivation practices between the sampling sites. 
Two soil columns (1 and 2) were collected from an undisturbed vegetated hillslope of the Amingaon watershed. The hillslope has an average slope of $20 \%$ along the main sloping direction with little microtopographic variations. About one meter deep coarse loam soil, classified under the hyperthermic family of Aquic Udifluvents (Vadivelu et al 2004) is evident in the hillslope. Subsurface geology indicates a two-layer soil formation, with a highly permeable coarse soil layer overlying a fine textured soil. An impermeable layer is present at about one meter depth from the land surface (Sarkar et al 2008). Soil textural properties determined from laboratory analysis of soil samples collected from the site are shown in table 2. The natural vegetation of the hillslopes mainly consists of close growing grasses and shrubs (e.g., Cynadon dactylon, Saccharum spontaneum, Mimosa pudica, Ageratum conyzoides, Ageratum haustonianum, Lantana camara, Mikania micrantha, Parthenium hysterophorus). The climate of the region has four primary seasons, namely, winter (DecemberFebruary), pre-monsoon (March-April), monsoon (May-September), and retreating monsoon (October- November). The 30-year average annual rainfall of the area is $1612 \mathrm{~mm}$ (Singh et al 2004).

Soil columns (3 and 4) were collected from two paddy fields of the Avayapur and Rudreswar Gaon watersheds within one month after crop harvesting. Both the fields are located in flat land and they have been under paddy cultivation for more than 100 years. These fields are prepared for paddy cultivation conventionally by thorough tilling and puddling of the topsoil. Such practice is essential to reduce deep percolation of ponded water as irrigation is an important aspect of cultivation. A minimum of two crops are grown annually and with irrigation facility a maximum of three crops per year can be cultivated. The soil textural properties of the two sampling sites are given in table 2. The climate and rainfall characteristics of the two watersheds are similar to that of the undisturbed hillslope site, as they are located close to each other (table 1 ).

For our comparative study of the effects of Jhum cultivation on infiltration patterns undisturbed soil columns were collected from different locations of the Waikhulok watershed of Manipur. This is a predominantly hilly watershed with an area of about $3.9 \mathrm{~km}^{2}$. Jhum cultivation is currently used on about $73 \%$ of the watershed area. Figure 2 shows different stages of Jhum cultivation in the Waikhulok watershed. The watershed has moderate relief and topographic features, with slopes ranging from 15 to $50 \%$. The subsurface geology is mainly formed by shale with intercalation of sandstone. Major soil groups of the region are Dystrochrept, Hapludalfs,
Hapludults, and Paleudalfs (Velayutham et al 1999). The soil textural class indicates a predominantly sandy loam soil. The climate of the watershed is classified as sub-humid with an average annual rainfall of about $1435 \mathrm{~mm}$. The climate is characterised by warm moist summer and cool dry winter (Seethapathi et al 2008). There are three distinct seasons comprising of summer (MarchMay), rainy season (June-October) and winter (November-February). The mean monthly maximum temperature ranges from $24.3^{\circ}$ to $32.7^{\circ} \mathrm{C}$ and mean monthly minimum temperature ranges from $3.2^{\circ}$ to $21.1^{\circ} \mathrm{C}$ (Bijayalaxmi and Yadava 2006). The native vegetation is dominated by evergreen trees, such as Haldi (Adina cordifolia), Sundi (Acer niveum), Toon (Cedrella toona), Jarul (Lagrostomia flosregina), Bonsum (Phoebe spp.), and Muli Bamboos (Melocanna bambusoides). Mixed forests are composed of Teak (Tectona grandis), Khen (Melanorhoa usitata), Semul (Bombax malabaricum), Pareng (Alnus nepalensis), and Pine (Pinus khasya). The land use of the watershed is primarily Jhum cultivated agriculture and horticultural crops (Seethapathi et al 2008). Random samples of soil columns were collected from an abandoned disturbed forest area (columns 5 and 6), which were fallow for approximately five years. Samples were also collected from Jhum cultivated crop fields such as paddy (columns 7 and 8), pineapple (column 9), and banana plantation (column 10). Under Jhum cultivation, upland paddy is grown as a broadcasted rainfed crop. Minimum tillage is the commonly practiced soil manipulation technique and only one crop per year is produced due to nonavailability of irrigation water supply.

\section{Methodologies}

\subsection{Experimental setup}

Undisturbed soil columns, each having a dimension of $25 \times 25 \times 50 \mathrm{~cm}$, were carved from a pedestal of soil block and then a rectangular chamber made of $6 \mathrm{~mm}$ thick Plexiglas sheet, was inserted from the top of the soil column by careful trimming of the excess soil around the sides of the column (figure 3). The samples were taken to the laboratory for the infiltration experiments. The laboratory experimental setup consisted of a soil infiltrometer chamber, a square overhead water tank, a square tray mounted on a stand, a hollow cylinder, and an outlet for excess water flow (figure 4). The Plexiglas collection chamber was used as infiltrometer chamber. The chamber containing the soil column was placed over the tray and the tank was securely attached above the soil column with screws. Rubber linings 


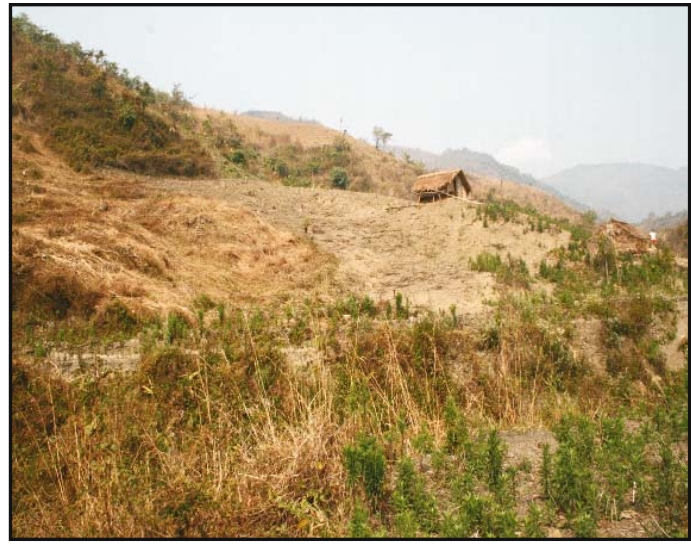

(a) Clearing of forests

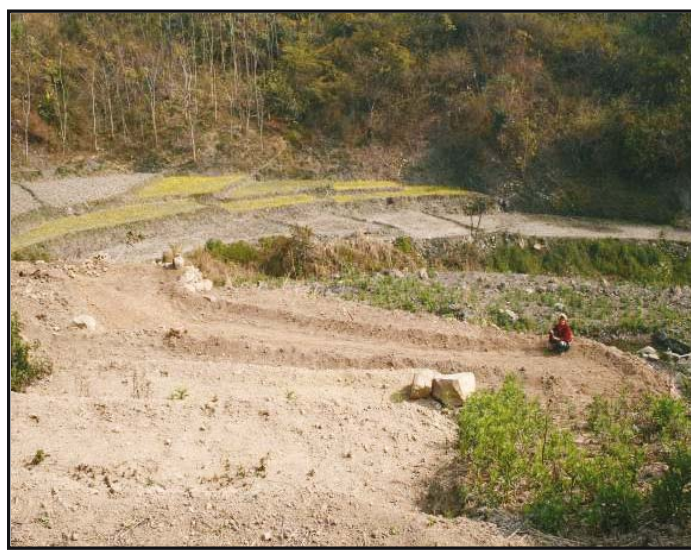

(c) Preparation of land for cultivation

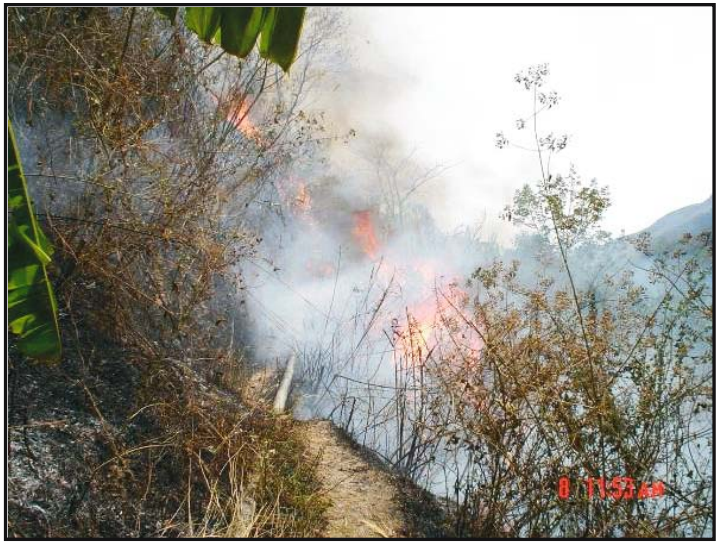

(b) Burning of forests

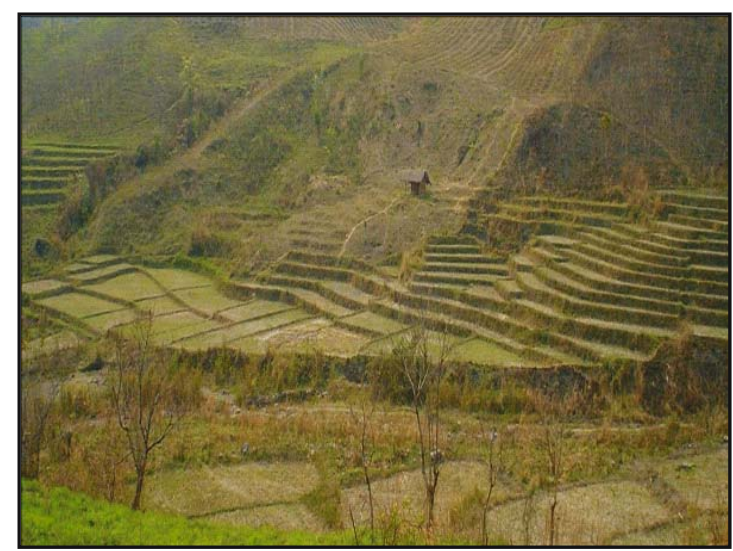

(d) Plantation of crops in the Jhum

Figure 2(a-d). Jhum cultivation in the Waikhulok watershed.
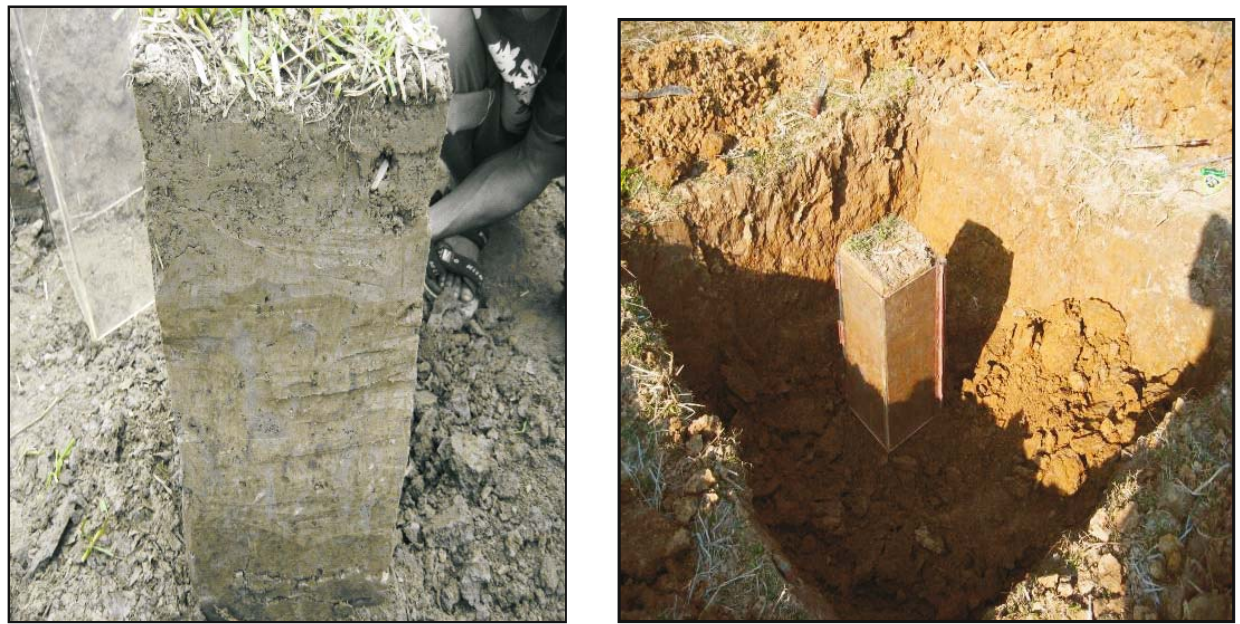

Figure 3. Collection of soil column from the field.

were used between the soil column and the Plexiglas chamber to minimize the leakage of dyed water. A one meter long and $2.5 \mathrm{~cm}$ diameter six sensor profile probe soil moisture meter (Delta T), equipped with a hand held data logger (Delta T), was inserted through the middle of the soil column down to the bottom of the hollow cylinder for monitoring the volumetric moisture content of soil. 


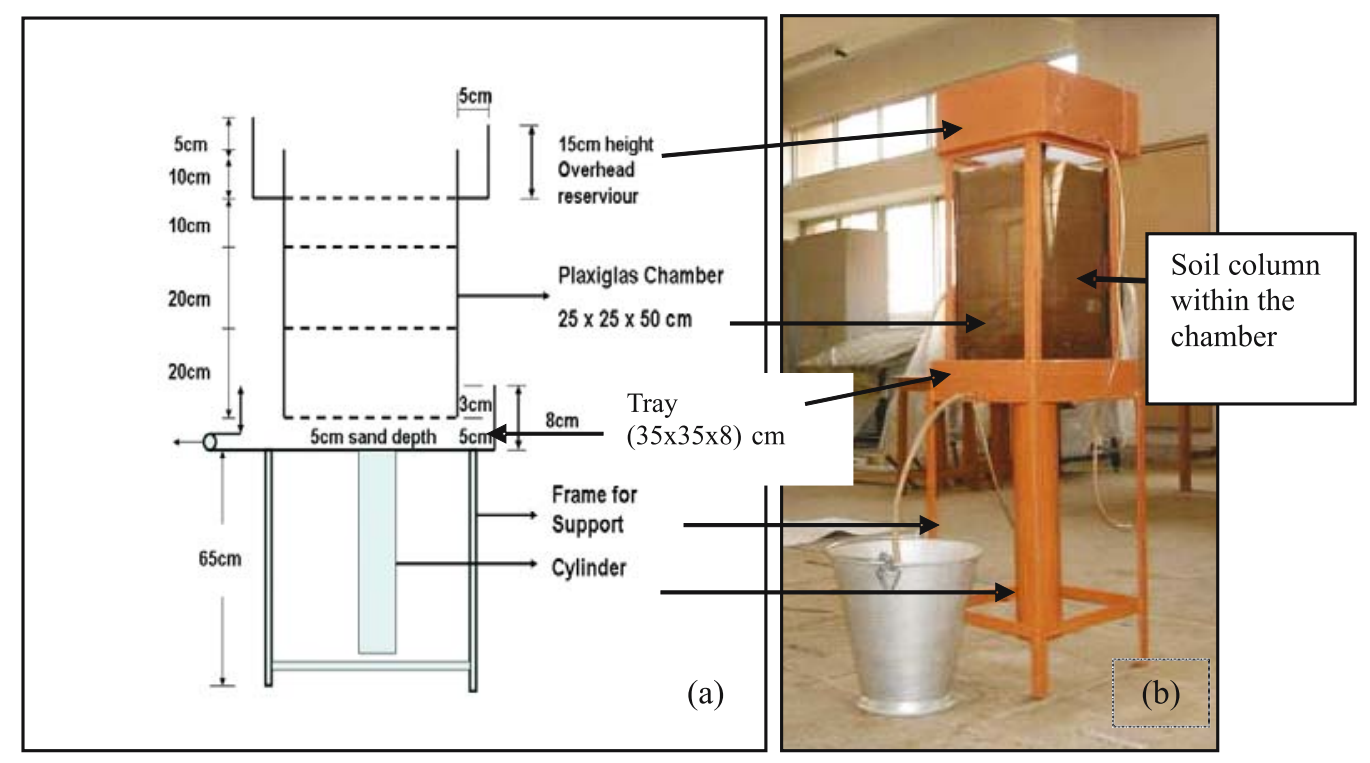

Figure 4. Laboratory setup for conducting dye infiltration experiments.

The instrument has multiple sensors to capture, display, and store the moisture contents at six different depths. To minimize the damage to the soil column a sharp soil auger was used to drill a $2.5 \mathrm{~cm}$ diameter hole.

In order to establish a wet initial condition each soil sample was subjected to infiltration with clear water for a period of 3 hours with a ponding depth of $2 \mathrm{~cm}$ maintained at the overhead water reservoir. By this time the profile probe readings indicated a steady state saturated condition of the soil column. Then the column was left for $4-5$ hours to allow the soil to attain field capacity. Dye infiltration experiments were then conducted. Brilliant Blue FCF $\left(\mathrm{C}_{37} \mathrm{H}_{34} \mathrm{~N}_{2} \mathrm{Na}_{2} \mathrm{O}_{9} \mathrm{~S}_{3}\right)$ is commonly used as a dye tracer and considered as one of the best available (Flury et al 1994; German-Heins and Flury 2000). It has low toxicity, high mobility, and high visibility even after dilution and adsorption (Weiler 2001). In the present study, Brilliant Blue R250 $\left(\mathrm{C}_{47} \mathrm{H}_{50} \mathrm{~N}_{3} \mathrm{O}_{7} \mathrm{~S}_{2}^{+}\right.$; C.I. 42660) dye, which belongs to the same family of Brilliant dyes and has similar staining characteristics like Brilliant Blue FCF, was used. Brilliant Blue R250 is also known to have better resolution of the stained objects (Merril 1990). The dye was applied at the rate of $4 \mathrm{~g} / \mathrm{l}$ which was sufficient for clear visibility of the stained macropore flow paths in soil.

Infiltration experiments were conducted with dye solution for each of the wet soil sample by maintaining a ponding depth of $2 \mathrm{~cm}$ in the overhead tank. This consideration is reasonable as the frequent high intensity storm events of the region can result in such ponded water on the soil surface. After 3 hours supply of dye solution was stopped and the soil was left for $4-5$ hours for allowing proper distribution of dye. Then the overhead tank and the Plexiglas chamber were removed and the soil column was sliced horizontally by a sharp edged thin plate at $1 \mathrm{~cm}$ intervals from the top to analyse the dye distribution patterns. The distortions in dye patterns due to slicing were negligible as the soils were not cohesive and had low water holding capacity. A graduated frame was placed on the soil surface to provide a reference for the image analysis. Serial image of each horizontal slice were taken using a digital SLR camera (Canon EOS 400D, 10 Mega Pixels resolution) for digital image analysis of the dye patterns.

\subsection{Image analyses}

For accurate measurement of stained areas, the serial images were colour corrected, digitally rectified, and scaled (figure 5) to a resolution of one square millimetre per pixel (Weiler and Flühler 2004). These corrected images were analysed to determine the characteristics of macropore flow behaviour for the soils subjected to different management practices. The stained paths indicated flow paths with continuous macropore connectivity. The unstained pores that are visible on a horizontal slice are the macropores for which the connectivity has been disturbed. Therefore, in relation to active macropore flow, the main area of interest was to quantify the stained path width and their distribution in both horizontal and vertical faces. Besides size of the stained paths, the distribution of these pores along different sections is to be described by means of spatial statistical parameters. Following the methods presented by Weiler (2001) and Weiler and Flühler (2004) 


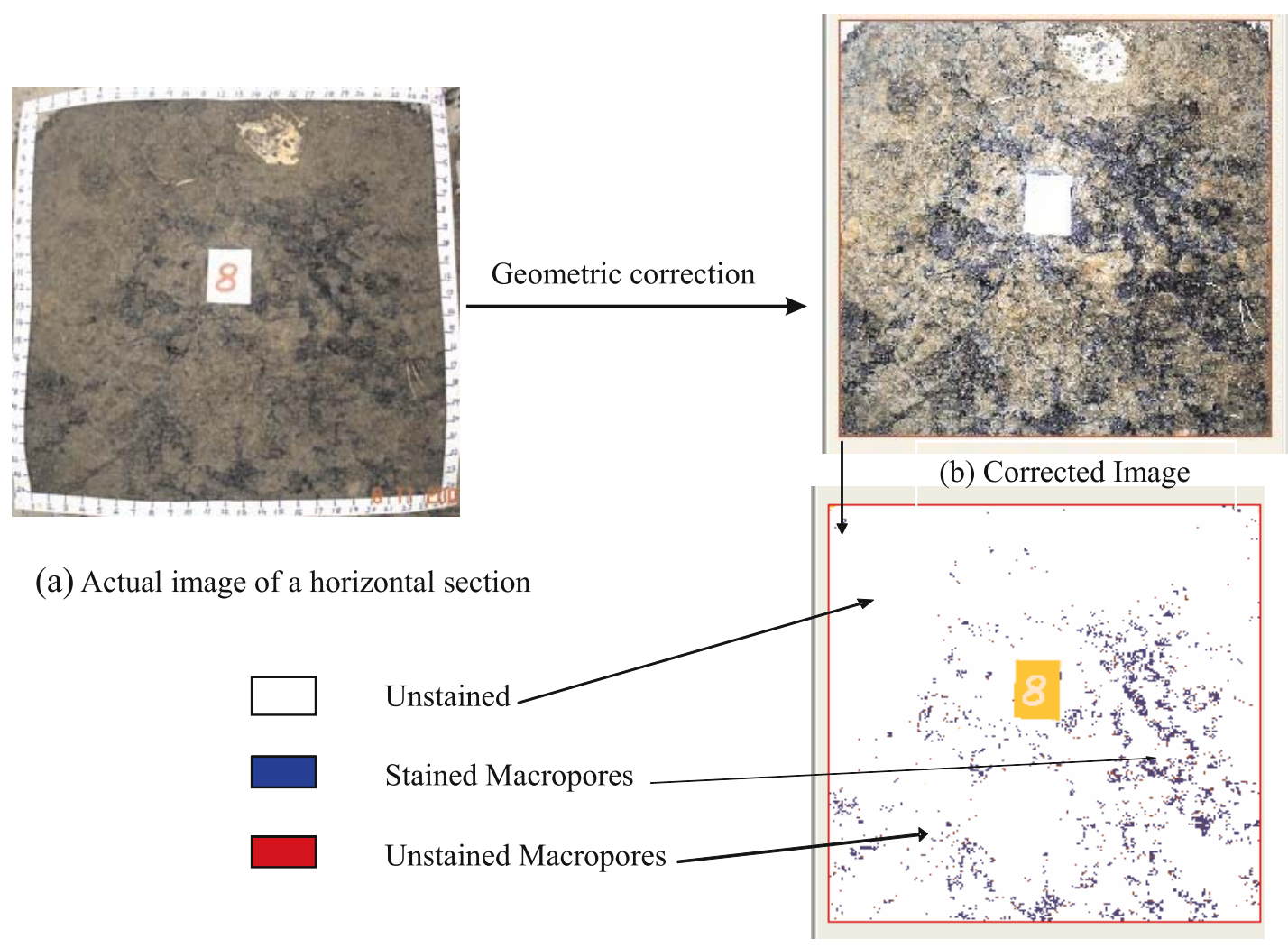

(c) Classified image

Figure 5. Image correction and classification for a horizontal section.

horizontal and vertical dye pattern analyses of the images were conducted.

\subsubsection{Horizontal dye pattern analysis}

Image analyses of the horizontal dye patterns were conducted to find the percentage dye coverage of the stained patterns for each horizontal section. The stained flow pathways obtained from dye tracer experiments were used to describe the preferential flow behaviour in soils. Quantitative parameters can be subdivided into basic and morphometric parameters such as the total stained area or a geometric description of stained objects and their spatial statistics. The objective of the horizontal dye pattern analyses was to find out the depth function of the percentage dye coverage area. The maximum likelihood algorithm available in Geomatica 10.0 software, was used to cluster the percentage dye coverage area of each horizontal image. A classification report after every image analysis was generated as percentage coverage area of the identified objects. Finally, classified images were compared with the original photographs to identify potential errors. The results of the percentage dye coverage area were summarized to indicate the percentage of stained flow path through each horizontal layer.

\subsubsection{Vertical dye pattern analysis}

The percentage dye coverage areas of horizontal images were used to calculate the statistical parameters of the vertical dye patterns. The vertical dye patterns provide a clear picture of the macropore flow processes at different depths. The basic parameter called volume density has been frequently used by the researchers for vertical dye pattern analyses (Weiler 2001; Weiler and Flühler 2004; Bachmair et al 2009). It is similar to the dye coverage area and can be derived by stereological methods. Stereology is a mathematical procedure used for relating three-dimensional parameters defining a structure to two-dimensional measurements obtained from the sections of the structure (Weibel 1979). The volume density $(V v)$ can be derived from one or two-dimensional information, as $V v$ can be related to the area density $\left(A_{A}\right)$ and length density $\left(L_{L}\right)$ as (Weiler 2001):

$$
V v=A_{A}=L_{L}
$$

The depth functions of the volume density with a vertical resolution of $1 \mathrm{~cm}$ were derived from the observed dye patterns. Four transect lines were taken at each depth to calculate volume density as 


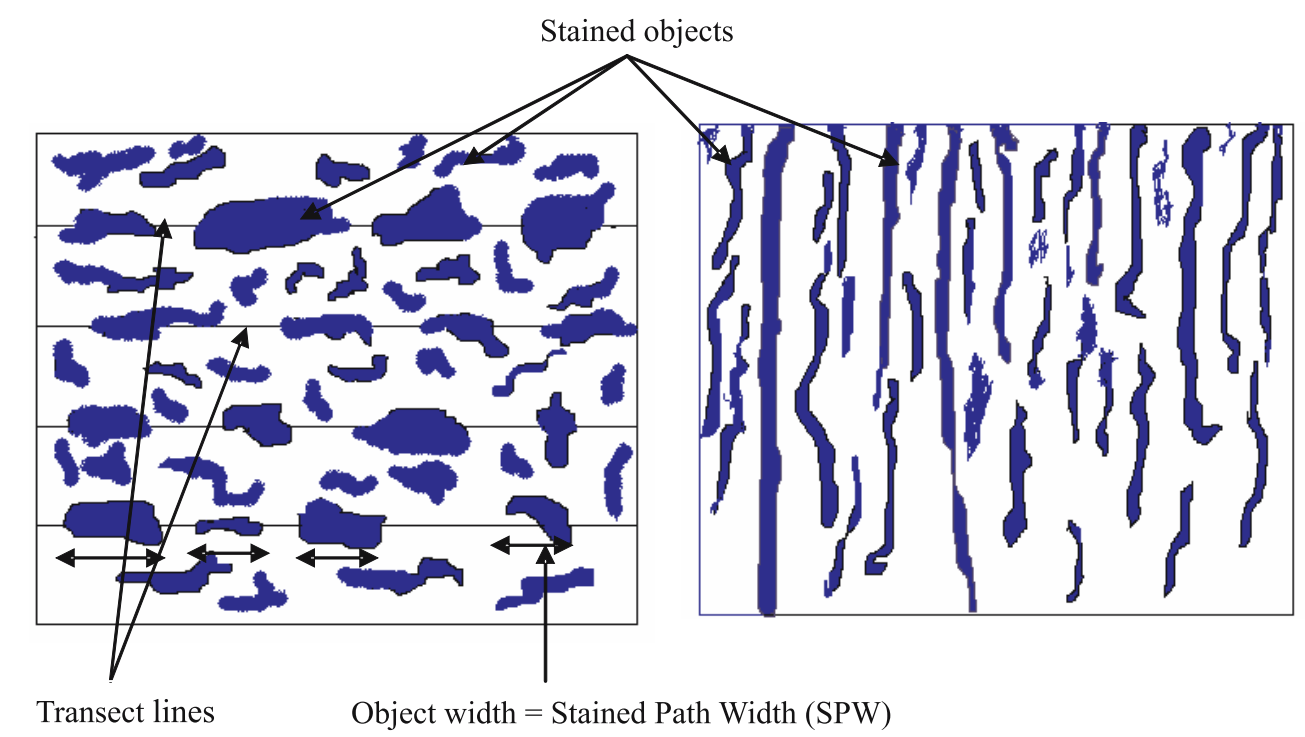

Figure 6. Object width and stained path width (SPW) of dye patterns.

the ratio of sum of the widths of intercepted stained objects to the total transect length (equation 2).

$$
\text { Volume density }=\frac{\sum S P W}{T_{L}},
$$

where $\sum S P W=$ sum of the widths of intercepted stained objects, and $T_{L}=$ total transect length.

The other important parameter that can be useful to describe preferential flow from vertical dye pattern analysis is the stained path width (SPW), which is the width of the stained objects for each soil depth. The one-dimensional intercept length can estimate the area of the object in two dimensions, if the object is isotropic (Weibel 1979). Therefore, the object width for a given depth of the vertical dye pattern was used as an indicator for the size of the object at that soil depth (Weiler 2001). As it may not be feasible to calculate the stained path widths for the entire horizontal slices at each depth, it is done in four transect lines. The resulting SPW was also used to derive statistical parameters such as maximum SPW and number of stained paths at each soil depth. Figure 6 shows the concept of transect lines and stained path widths taken on a horizontal surface and an arbitrary distribution of macropore pathways as may be visible on a vertical section. Here the object widths are referred to as stained path widths. After counting the number of stained paths they were grouped into five SPW classes. Then the depth distribution of the number of stained paths in each group was taken to calculate the volume density. For a particular section, volume density was calculated as the total number of stained paths divided by the width of the section. Thus from the frequency distribution of the SPW at each section the volume density related to the SPW classes were determined. The depth function of stained path width was derived by combining all vertical dye patterns.

\section{Results}

\subsection{Horizontal dye pattern analysis}

Horizontal dye pattern analysis was carried out for all the 10 soil columns for each horizontal section at $1 \mathrm{~cm}$ depth intervals. The horizontal dye patterns provide detailed information about the maximum depth of dye penetration and percentage dye coverage of the sections. For every soil column percentage dye coverage versus depth was plotted.

Figure 7(a and b) shows the depthwise distributions of dye coverage (\%) for undisturbed hillslope soil columns (columns 1 and 2). Column 1 had maximum dye coverage of $9.91 \%$ at $5 \mathrm{~cm}$ depth and an average of $3.71 \%$, whereas column 2 had maximum dye coverage of $7.42 \%$ at $9 \mathrm{~cm}$ depth and an average of $2.77 \%$. In both of the columns, the dye penetration was visible up to the last soil layer. This indicates the presence of continuous macropores throughout the soil column. Such distribution of macropores can be expected from densely vegetated undisturbed hillslope soils where growth of plant roots provides preferential pathways for water movement. The occurrence of maximum dye coverage within $10 \mathrm{~cm}$ depth also represents higher root density and activity of soil fauna in the top soil layer. From the average dye coverage, it can 


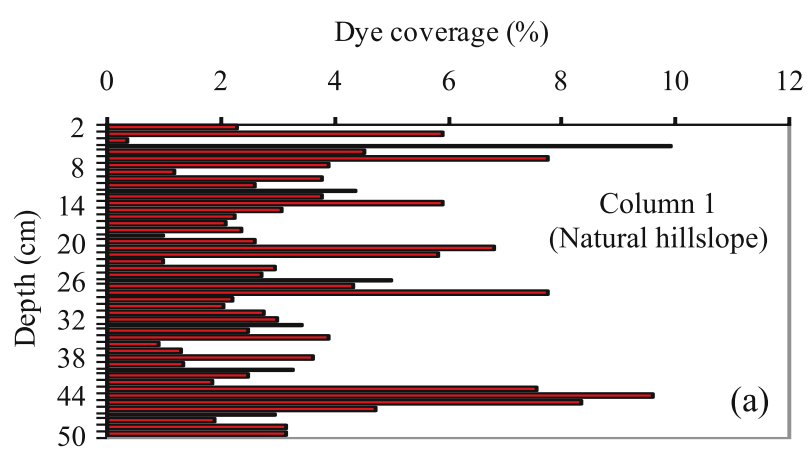

Dye coverage $(\%)$

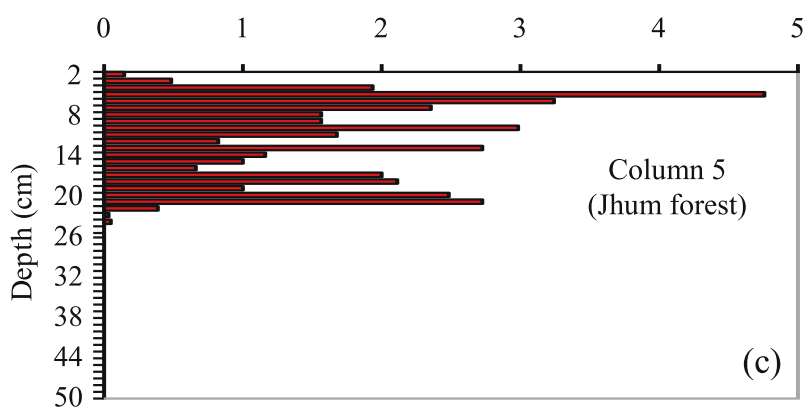

Dye coverage $(\%)$

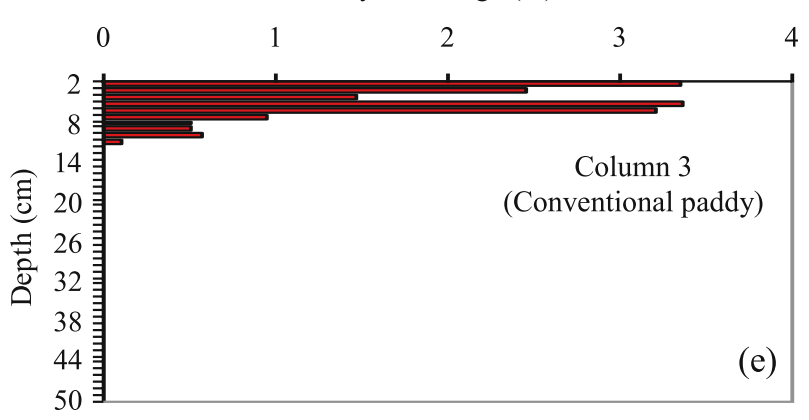

Dye coverage $(\%)$

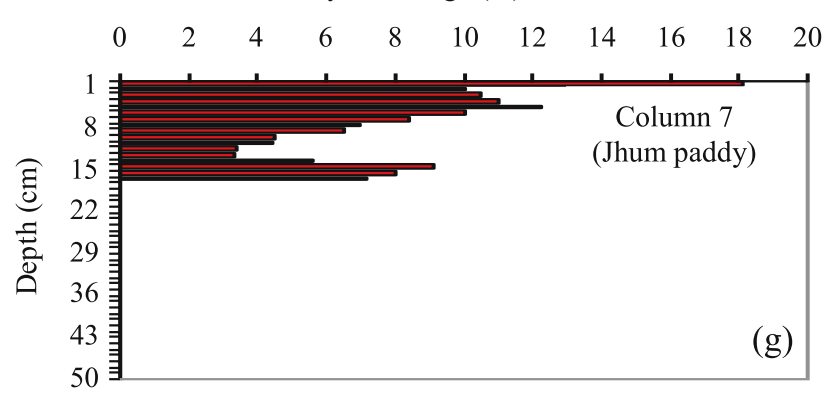

Dye coverage $(\%)$

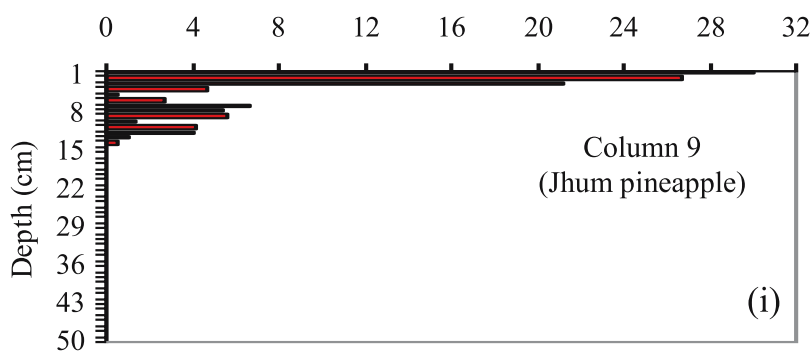

Dye coverage $(\%)$

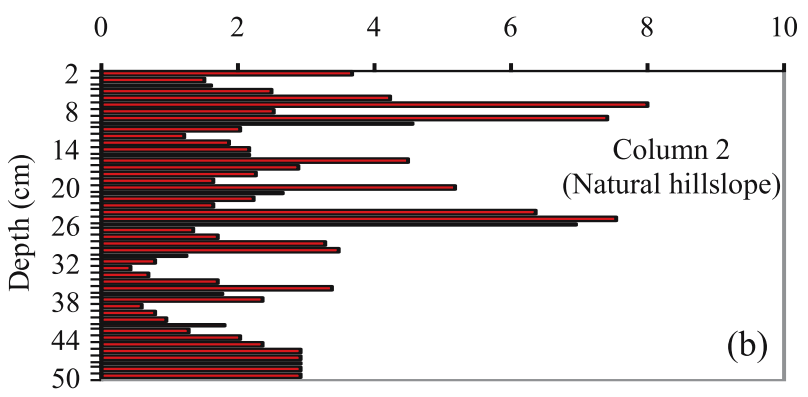

Dye coverage (\%)
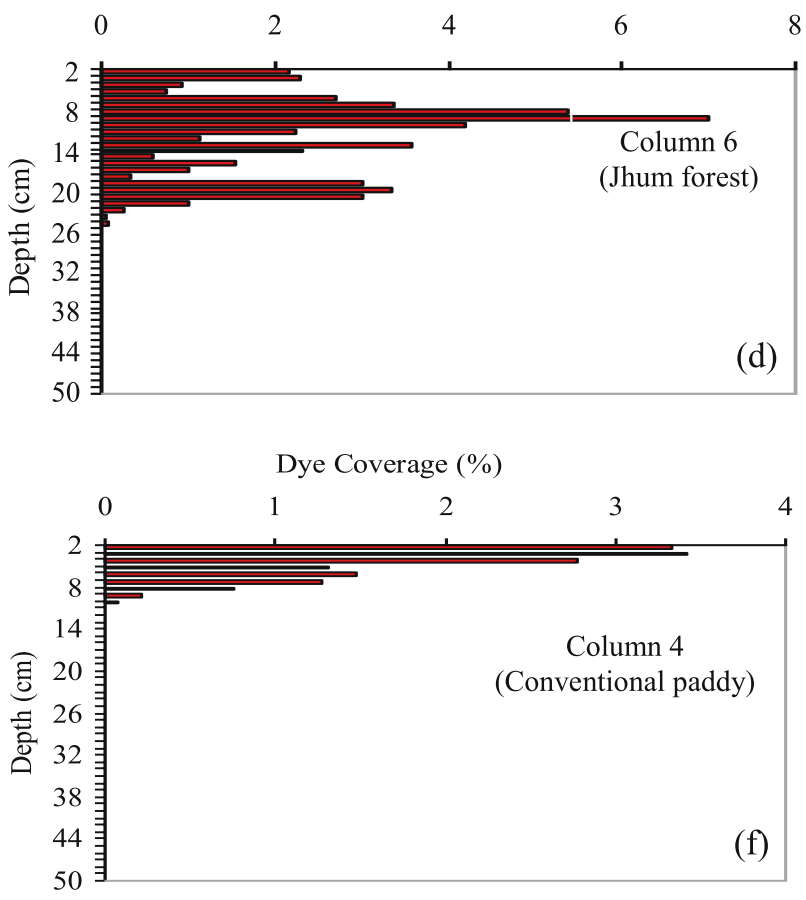

Dye coverage $(\%)$

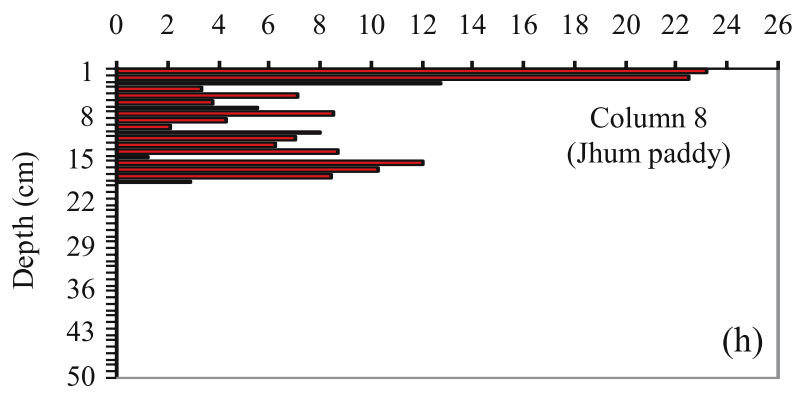

Dye coverage (\%)

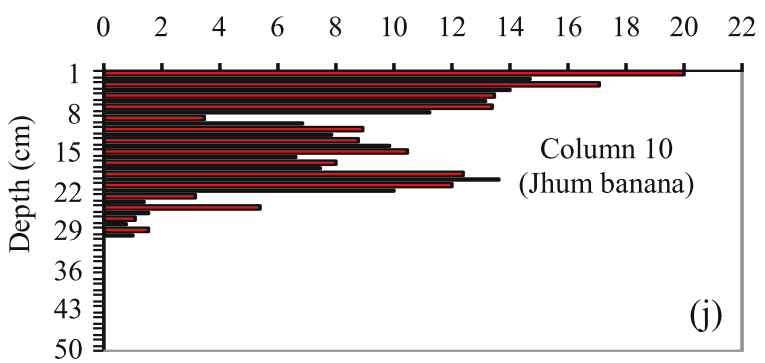

Figure $7(a-j)$. Depthwise dye coverage distribution of the soil columns. 
be noted that most of the flow pathways were concentrated to $3.71 \%$ and $2.77 \%$ of total area in columns 1 and 2, respectively. Figure 7 (c and d) shows the dye coverage distributions for the disturbed forests which were abandoned after Jhum cultivation (columns 5 and 6 ). In column 5 , the maximum dye coverage was observed as $4.75 \%$ at $5 \mathrm{~cm}$ depth and an average of $1.64 \%$, whereas in column 6 , the maximum dye coverage was $7.00 \%$ at $9 \mathrm{~cm}$ depth with an average of $2.17 \%$. This indicates that the average flow path was $1.64 \%$ in column 5 and $2.17 \%$ in column 6 . A different trend in the dye coverage pattern can be observed from these two soil columns. In column 5, maximum depth of dye penetration was $24 \mathrm{~cm}$ and for column 6 , it was $25 \mathrm{~cm}$. This can be mainly attributed to the effects of Jhum cultivation. In the process of Jhum cultivation, the natural soil structure and macroporosity of the natural forest soil were disturbed completely. The process of clearing and burning of forest cover and the earthwork required to convert the slopes into nearly level agricultural fields significantly altered the structure of the topsoil. Therefore, the subsurface macropores lost their surface connectivity. In addition, during agricultural production any form of soil manipulation led to breaking of the soil aggregates and the finer soil particles filled the macropores permanently. After abandonment the top soil layer (up to $25 \mathrm{~cm}$ ) regained some macroporosity due to regrowth of vegetation, but the underlying soil layers were yet to recover their natural macroporosity. Similar behaviour was also reported by Ziegler et al (2004). The results indicate the long term effects of macropore sealing in lower soil layers due to Jhum cultivation and the resulting change in water flow patterns through soil.

Comparison of the horizontal dye patterns obtained from soil samples collected from conventional paddy fields (columns 3 and 4) and Jhum cultivated paddy fields (columns 7 and 8) showed some interesting results. Figure 7 (e and f) depicts the dye patterns of conventional paddy fields, whereas figure $7(\mathrm{~g}$ and $\mathrm{h})$ shows the dye patterns of Jhum cultivated paddy fields. In both the cases, a decrease of percentage dye coverage with depth was evident. In the conventional paddy field soils the maximum depth of dye penetration was $10 \mathrm{~cm}$ and its propagation after that became negligible. The average dye coverage up to $10 \mathrm{~cm}$ depth was $1.65 \%$ for column 3 and $1.63 \%$ for column 4 . The dye pattern distributions varied spatially and quantitatively in both of the soil columns, but average dye distribution and the maximum depth of dye penetration were similar. The low penetration of dye was due to prolonged paddy cultivation (>100 years) which causes the formation of a hard pan below the puddled depth (Chen and Liu 2002;
Mishra et al 2008). Interestingly, the Jhum cultivated paddy field soils showed higher depth of dye penetration than conventional paddy fields (figure 7). Maximum depths of dye penetration were found to be $17 \mathrm{~cm}$ and $19 \mathrm{~cm}$ for columns 7 and 8 , respectively. The horizontal dye patterns showed the average percentage dye coverage for column 7 was $7.57 \%$ and that for column 8 was $7.49 \%$. The results indicated no formation of hard pan below the puddled layer as in the case of conventional paddy fields. This may be attributed to the fact that under Jhum cultivation paddy is cultivated as a broadcasted rainfed crop with minimum tillage and no puddling is required as transplanting of seedlings is not done. Also these paddy fields were recently converted from natural forests and they are in the initial $2-3$ years of cultivation. Though the process of slashing and burning of forest vegetation, rigorous land preparation, and subsequent agricultural activities imparted the sealing of macropores beyond a certain depth, the topsoil retained some macroporosity without any evidence of hard pan formation.

Figure 7(i and $\mathrm{j})$ shows the horizontal dye coverage percentage at different depths for the pineapple (column 9) and banana (column 10) plantations. The maximum depth of dye penetration was $14 \mathrm{~cm}$ for column 9 and $30 \mathrm{~cm}$ for column 10, whereas the average dye coverage was $3.32 \%$ and $7.67 \%$ for columns 9 and 10, respectively. The variation in dye penetration depth was due to the different rooting characteristics of pineapple and banana. The banana plantation field had a more mature root network as they were much older than the pineapple plants, which are planted every year. Banana plants have high demand of water and therefore, higher root penetration depth is expected. Whereas, pineapple plants are shallow rooted and yearly land preparation for planting destroys the macropores. It is also worth mentioning that four years back these two fields, under banana and pineapple plantation, were put under paddy cultivation. Once the soil became unable to meet the fertility demand of paddy, they were converted into fruit plantations before finally abandoning the land. Therefore, a significant change in the number of macropores and their connectivity was evident in these soils.

\subsection{Vertical dye pattern analysis}

Vertical dye pattern analysis was carried out to derive the parameters volume density, stained path width at different transects, depthwise distribution of SPW and maximum SPW at the transects. These parameters were analysed to interpret the soil macropore structure and the process of water 
Table 3. Distribution of average volume density with SPW at a particular transect.

\begin{tabular}{lllllc}
\hline $\begin{array}{l}\text { SPW } \\
\text { range } \\
(\mathrm{mm})\end{array}$ & $\begin{array}{c}\text { Column 1 } \\
\text { (natural } \\
\text { forest) }\end{array}$ & $\begin{array}{c}\text { Column 3 } \\
\text { conventional } \\
\text { paddy) }\end{array}$ & $\begin{array}{c}\text { Column 6 } \\
\text { (Jhum } \\
\text { forest) }\end{array}$ & $\begin{array}{c}\text { Column 8 } \\
\text { (Jhum } \\
\text { paddy) }\end{array}$ & $\begin{array}{c}\text { Column 9 } \\
\text { (Jhum } \\
\text { pineapple) }\end{array}$ \\
\hline $1-2$ & 0.027333 & 0.00168 & 0.00840 & 0.00568 & 0.00680 \\
$3-4$ & 0.020500 & 0.00112 & 0.00288 & 0.00160 & 0.00128 \\
$5-7$ & 0.010583 & 0 & 0.00352 & 0.00040 & 0.00048 \\
$8-10$ & 0.004583 & 0 & 0 & 0 & 0 \\
$>10$ & 0.001444 & 0 & 0 & 0 & 0 \\
\hline
\end{tabular}

movement through the soil columns. A clear indication of soil macroporosity in terms of their size and depthwise distribution can be derived from the analysis.

The SPWs determined at each transect were classified into five groups based on their size. Table 3 enumerates average volume densities of different SPW classes at a particular transect for soil columns representing different land use and land cover patterns. The results show that the undisturbed vegetated hillslope soil (column 1) has high degree of macroporosity throughout its soil profile. The SPW classes 1-2 mm and 3-4 mm are dominating, which indicates that most of the macropores present in the soil have sizes in the range of $1-4 \mathrm{~mm}$. Macropores greater than $4 \mathrm{~mm}$ in diameter are comparatively much less in number. The conventional paddy field soil (column 3) did not show significant macroporous structures. Under Jhum cultivated forest and plantation field soils (columns 6, 8, and 9) no macropores having a size greater than $7 \mathrm{~mm}$ were evident. However, small diameter macropores $(1-2 \mathrm{~mm})$ dominated the soil profiles in all the 10 soil columns.

Figure $8(\mathrm{a}-\mathrm{e})$ depicts the depthwise distribution of number of stained paths encountered at a particular transect for different soil columns. Column 1 had the highest number of stained paths of 27 at $45 \mathrm{~cm}$ depth. This indicates good connectivity of the macropores in the soil profile. The maximum sizes of SPWs found at different depths were in the range of $2-23 \mathrm{~mm}$. In column 3 , the nature of dye penetration indicated less macroporosity in the soil profile as in paddy fields; the natural soil macropores are destroyed in the process of puddling. For soil columns 6 and 8 no evidence of macropores was found below $25 \mathrm{~cm}$ depth, whereas column 9 showed no sign of macropores below $15 \mathrm{~cm}$ depth. This is due to the effect of Jhum cultivation which has disturbed the macropore connectivity in the lower horizons of soil. Column 6 had a maximum number of SPW of 7 at $10 \mathrm{~cm}$, $19 \mathrm{~cm}$, and $20 \mathrm{~cm}$ depths. Columns 8 and 9 showed a maximum number of 11 stained paths occurring at $5 \mathrm{~cm}$ and $1 \mathrm{~cm}$ depths, respectively. Maximum SPW range for soil columns 6, 8, and 9 were
1-7 mm, 1-5 mm, and 1-6 $\mathrm{mm}$, respectively. Macropores greater than $7 \mathrm{~mm}$ diameter were not present as they might have been disturbed due to soil manipulation during crop productions. Figure 9 shows that the volume density has a better correlation with the number of stained paths than with the maximum width of the stained paths. This is because the large diameter macropores are few in number and therefore the volume density is mostly influenced by the smaller macropores which are more in numbers.

\section{Discussion}

\subsection{Influence of land use and land cover on macroporosity}

The differences in soil type, soil texture, bulk density, climate, and fauna can influence soil macroporosity to some extent. However, results of the present study show that the most significant variable that provides first-order control of the effective soil macroporosity is vegetation and its root network. This finding is also consistent with findings elsewhere. A particular soil can have several numbers of structural voids, cracks or fissures. But these may not be active flow paths for water if they do not get the connectivity. Vegetation roots are known to create new flow paths as well as establish connectivity between the existing preferential pathways to make them hydrologically active (Beven and Germann 1982; Ziegler et al 2004; Scanlan and Hinz 2007; Sarkar et al 2008b). Therefore, a strong correlation can be found between vegetation density and preferential flow rate (Sarkar et al 2008a). In soils with high densities of macropores, infiltration is primarily controlled by preferential flow network. The factors like clay content and bulk density affect the soil matrix flow and matrix-macropore interaction process, which is much less as compared to macropore flow rate. The inherent properties of soil (texture, structure, bulk density, and porosity) may be responsible for the structural voids present in a particular soil. But the vegetation dynamics as 


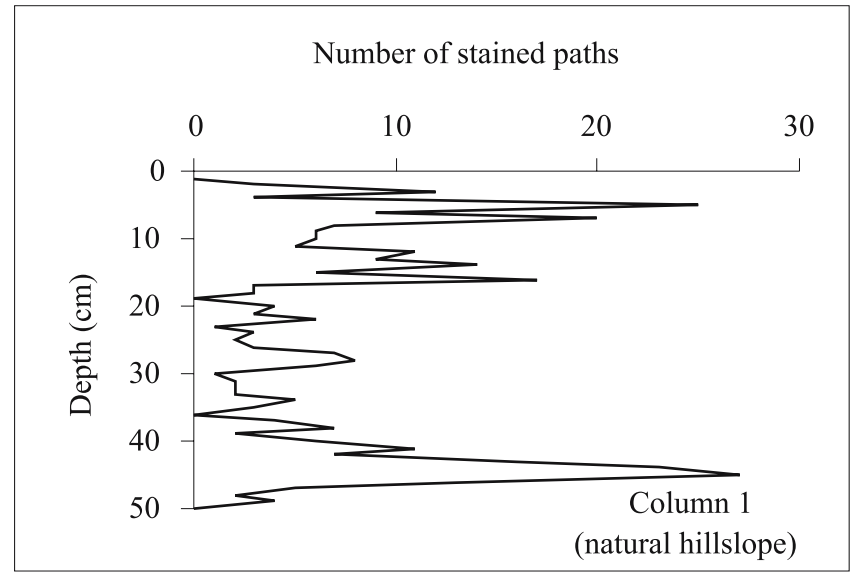

(a)

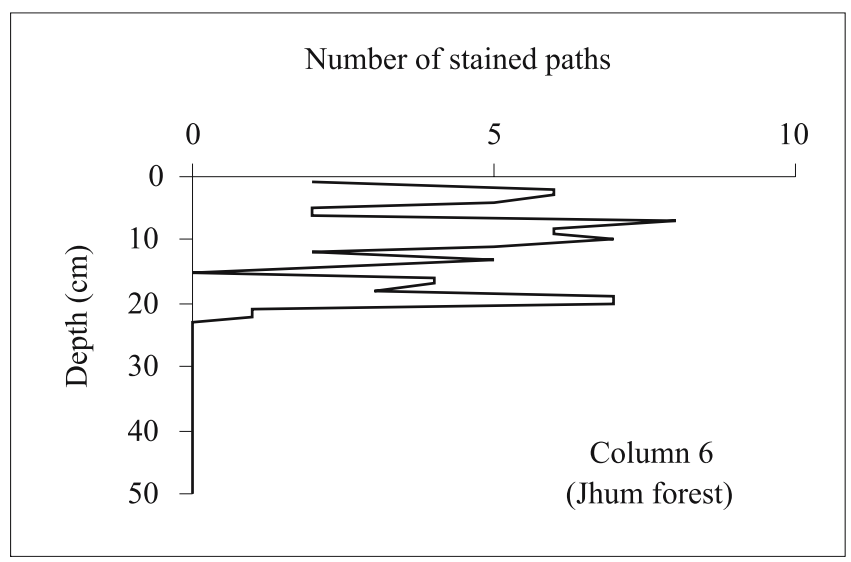

(c)

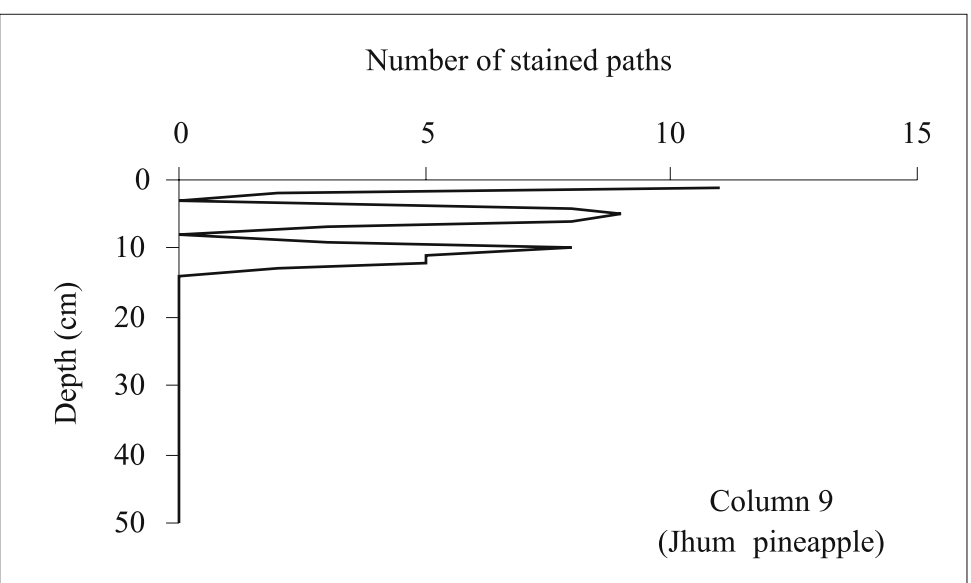

(e)

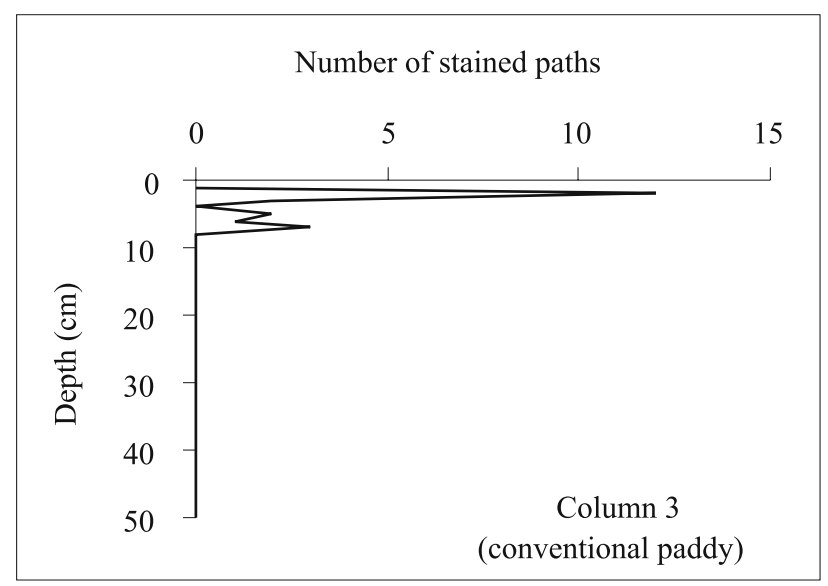

(b)

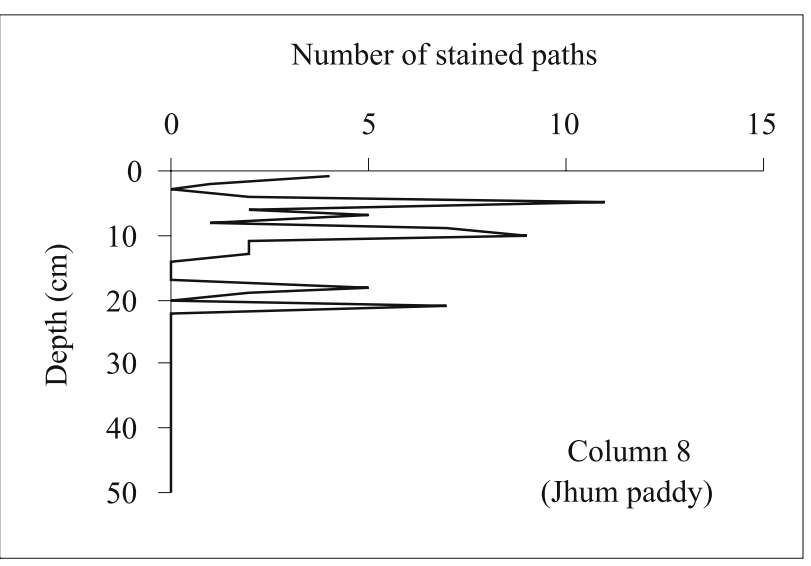

(d)

Figure 8. Depthwise distribution of number of stained paths under different conditions.

influenced by land use and land cover is the most critical factor which imparts hydrological effectiveness to the soil macropores.

Management practices like Jhum cultivation and subsequent operations such as tillage and other forms of soil manipulations can destroy the surface connected macropores in the topsoil (Olsen and Børresen 1997). The stage of Jhum cultivation may also be an important parameter to represent the soil macroporosity. The effects of Jhum cultivation can be described as short term effects and long term effects. Short term effects occur immediately after a forest land is converted to agricultural land by burning, cleaning, and manipulating the soil. The process completely destroys the macropore network in the topsoil to result in less 

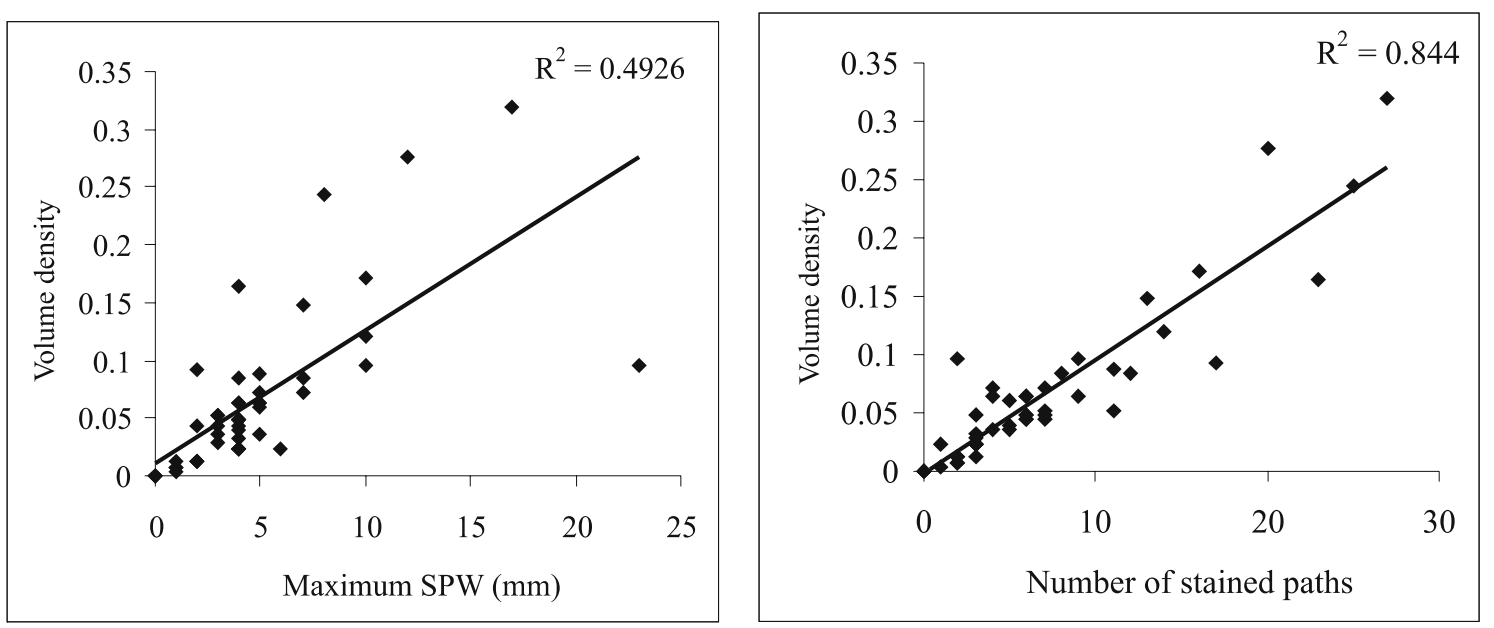

Figure 9. Correlation of volume density with maximum SPW and number of stained paths.

infiltration and high sediment and surface runoff generation (Ziegler et al 2004). Disproportionate runoff generation can lead to the occurrence of floods during monsoon seasons. Frequent overland flow generation on freshly exposed loose and bare soil surface can cause accelerated soil erosion. The eroded fine particles can seal the surface initiated macropores resulting in loss of macropore connectivity from the top. Therefore, during the cultivation stage undisturbed macropores present in the subsoil may not be active due to lack of connectivity. Such behaviour can be evident all throughout the period of agricultural production in Jhum cultivated fields. Once the land is abandoned, the natural vegetation establishes to initiate the soil macropore connectivity. However, it may take a long time (15-25 years) to re-establish complete connectivity throughout the soil profile (Ziegler et al 2004). Therefore, after abandonment the infiltration capacity of the soil gradually increases, overland flow rate decreases, and due to growth of vegetation soil erosion and sediment production are reduced. These are the long term effects of Jhum cultivation which influences the infiltration behaviour, solute transport, stormflow generation, and rainfall-runoff processes of the watersheds for a prolonged period.

Our observations can be used to show this hydrological recovery of soil following field abandonment. The undisturbed forested hillslope soil had the highest degree of macroporosity and continuous preferential pathways throughout the soil profile. Conventionally cultivated paddy fields had very little macroporosity as soil puddling significantly altered the natural soil structure. The Jhum cultivated lands reflected its short and long term effects on soil macroporosity. The active soil macropore network was closely related to the factors like type of crop and their rooting characteristics, method of cultivation, land preparation and tillage practices, and current stage of the Jhum cycle. Jhum cultivation can change the macroporosity of soils for a long period of time and can have several adverse effects on natural equilibrium and sustainability (Goswami 1980; Sharma 1992; Tuan 1993; Gafur et al 2003; Pagliai et al 2004; Ziegler et al 2004). Therefore, limiting the amount of land under Jhum cultivation, promoting alternate cultivation methods (Sanchez and Hailu 1996) and allowing for sufficient recovery time should help to reduce possible land and water resource impacts of Jhum cultivation.

\subsection{Applications of the experimental data}

Preferential infiltration through soil macropores has been identified as the first order control of processes related to several issues such as leaching of fertilizers, chemicals, and pollutants, rapid stormflow generation in hillslopes, flash flooding in rivers, and hydrological response of watersheds. Clear understanding of macropore flow process is essential for addressing these problems. But in macroporous soils most of the existing flow models provide unsatisfactory results as they do not capture the relevant processes (Weiler 2005). The primary soil data that may be required for defining macropore flow process are size, connectivity, density, and depth distribution of macropores. These parameters combined with soil matrix data can be used to describe the three basic aspects of macropore flow: infiltration of water into macropores, initiation of macropore flow, and interaction between macropores and surrounding soil matrix (Weiler 2005). The data collected from dye tracer experiments provide the quantitative information which may be required as an input to models developed for addressing different phenomena related to preferential infiltration (Jarvis et al 1991; Borah and Kalita 1999; Weiler and Naef 
2003; Weiler 2005; Sarkar and Dutta 2009). Surface and subsurface initiation of macropores also control water flow in macropores and transfer of water from macropores to the surrounding soil matrix (Weiler and Naef 2003). This affects the subsurface wetting patterns and solute transport in soils. Depth distribution of macropore density obtained from dye tracing can indicate the surface and subsurface initiated macropores to help in defining the macropore drainage area (Weiler and Naef 2003). Apart from these, the field data of dye patterns can be compared with model simulations to evaluate the model performance (Weiler 2005).

In agricultural watersheds diverse land use and land cover patterns are often encountered. As land use and land cover influences soil macroporosity, differences in infiltration characteristic is expected to occur in different parts of the watershed. Therefore, runoff generation from these watersheds are controlled by the variation of macroporosity as influenced by the existing land use and soil structure. Similar to Bachmair et al (2009), our data show how vegetation and crop production techniques can affect the macroporosity of soils. We also suggest that land use effects on soil properties, such as those presented here, need to be considered in hydrological models to obtain better predictions of water quality and quantity.

The velocity of water and solute transport through a system of soil matrix and macropores is much faster than the hydraulic conductivity of the soil matrix alone. Therefore, to model flow and transport processes in macroporous soils, a high value of effective hydraulic conductivity is commonly adopted (Sloan et al 1983; Fan and Bras 1998; Troch et al 2002; Rezzoug et al 2005). Measurement of flow velocity with ion tracers can be useful to select a reasonable value of the effective hydraulic conductivity of a matrix-macropore system. Dye tracing methods can also be helpful in approximately selecting a suitable range of effective hydraulic conductivity as the dye patterns reflect the extent of macropore connectivity and active flow paths within the soil. Thus, the experimental data collected from the present investigation may have wide range of applications in several land and water resources related issues of the region.

\subsection{Scopes of improvement for future studies}

For future studies, the use of ion tracers for conducting infiltration tests can be more useful, as in dye tests the soil columns are destroyed and no information about the flow velocity through soil macropores can be obtained. Small scale tracer experiments can be used to explore the preferential flow velocity distribution (Weiler and Naef 2003). Use of ion tracers can also provide spatial and temporal data on solute transport and their travel time. Elçi and Molz (2009) used bromide tracer to measure actual travel time of water flow in macroporous soils. They found that the soil matrix permeability was much less than the measured soil matrix plus macropore permeability. The use of the measured higher value of permeability resulted in better simulation of their numerical subsurface flow model (MODFLOW). Buttle and McDonald (2000) suggested that tension infiltrometry can be a rapid and non-destructive method of assessing spatial variations in the relative contribution of macropore flow to the infiltration process. For monitoring and understanding the soil water processes, geophysical methods can also be helpful as they are non-invasive and do not disturb either the structure or the water dynamics of the soil. Batlle-Aguilar et al (2009) used electrical resistivity tomography (ERT) for imaging water infiltration dynamics in soil with a tension infiltrometer using $\mathrm{Cl}^{-}$and $\mathrm{Br}^{-}$solution as tracer. The method was used to determine soil hydraulic conductivity and sorptivity values. A similar method of determining bulk density and macroporosity of soil is computer tomography (CT). It is also a non-destructive method of obtaining spatial density distribution of macropores and visualizing solute infiltration in soils (Olsen and Børresen 1997). Thus, the information about size and density distribution of soil macropores, active flow network, flow velocity, and distribution of pore water pressure can be used to better describe the infiltration process, which can help in the process-based modelling approach in hillslope hydrology (Weiler and McDonnell 2004).

\section{Conclusions}

The present study compared the effects of common land use and management practices on the macroporosity of soils in northeast India. Dye infiltration experiments combined with digital image processing provided a clear picture of the variations in dominant flow processes through the soils subjected to different land uses. The undisturbed forested hillslope soils showed the presence of continuous macropores distributed throughout the depth of the soil profile. Macropore density was high in the topsoil up to a depth of $10 \mathrm{~cm}$ and the overall soil macroporosity was dominated by $1-4 \mathrm{~mm}$ diameter macropores. In conventional paddy fields, due to formation of hard pan near the soil surface, dye penetration depth was restricted to only $10 \mathrm{~cm}$. This can be attributed to the frequent tilling and puddling of the topsoil of paddy fields. On the other hand, the soil columns collected from paddy fields of Jhum cultivated plots showed 
comparatively higher depth of dye penetration (about $20 \mathrm{~cm}$ ). This is mainly due to the differences in the land use, land cover and management practices such as degree of tillage and local methods of crop production which varied between the sites. Jhum cultivated pineapple fields showed signs of soil macropores up to a depth of $14 \mathrm{~cm}$, whereas that of banana plots were much higher $(30 \mathrm{~cm})$ due to more established root network. It was evident that the process of Jhum cultivation significantly reduced the macroporosity of forest soils and afterwards their macroporosity largely depended on the type of the crops cultivated. It was also observed that after abandonment of the Jhum plots the topsoil attained some macroporosity due to re-growth of vegetation, but there was still poor connectivity below $25 \mathrm{~cm}$ depth. Jhum cultivation also destroyed larger macropores, having diameters greater than $7 \mathrm{~mm}$, completely.

These experimental results derived from the present study revealed that the practice of Jhum cultivation had lasting effect on soil structures. Effect of land use and land cover on soil macroporosity was also prominent. These experimental data can have wide applications in different cases of preferential flow and transport processes in the region. To describe the process of vertical infiltration into macroporous soils the data related to the number and size distributions of active macropores, average size of macropores, surface and volume density of macropores, and depthwise distribution of macropores, should be useful. Dye tracing experiments provide these quantitative information which can be used to describe the processes like macropore flow initiation, storage capacity of the macropores, and the interaction between soil matrix and macropore flow. Collection of detailed data of soil macroporosity from different parts of northeast India may be helpful for assessing the impacts of different land use and land cover and local crop management practices on soil structures. This should give a better understanding of macropore dominated flow and transport processes occurring in the region.

\section{Acknowledgements}

This research project was financially supported by the Remote Sensing Application Mission (RSAM) programme under the Department of Space (DOS), India. The authors are thankful to Dr S Panigrahy and Dr J S Parihar, Space Applications Centre (SAC), Indian Space Research Organization (ISRO), Ahmedabad, India. We are also grateful to Prof. Arun Kumar, Earth Science Department, Manipur University, India for providing valuable information about the Waikhulok watershed. We express our sincere thanks to the four anonymous reviewers for offering their valuable suggestions and critical comments, which have improved the quality of the paper.

\section{References}

Alansi A W, Amin M S M, Abdul Halim G, Shafri H Z M, Thamer A M, Waleed A R M, Aimrun W and Ezrin M H 2009 The effect of development and land use change on rainfall-runoff and runoff-sediment relationships under humid tropical condition: Case study of Bernam watershed Malaysia; European J. Sci. Res. 31(1) 88-105.

Alaoui A and Goetz B 2008 Dye tracer and infiltration experiments to investigate macropore flow; Geoderma 144(1-2) 279-286.

Anderson A E, Weiler M, Alila Y and Hudson R O 2008 Dye staining and excavation of a lateral preferential flow network; Hydrol. Earth Syst. Sci. Discuss. 5 1043-1065.

Andreini M S and Steenhuis T S 1990 Preferential paths of flow under conventional and conservation tillage; Geoderma 46 85-102.

Bachmair S, Weiler M and Nützmann G 2009 Controls of land use and soil structure on water movement: Lessons for pollutant transfer through the unsaturated zone; J. Hydrol. 369 241-252.

Batlle-Aguilar J, Schneider S, Pessel M, Tucholka P, Coquet Y and Vachier P 2009 Axisymetrical infiltration in soil imaged by noninvasive electrical resistivimetry; Soil Sci. Soc. Am. J. 73 510-520.

Beven K and Germann P 1982 Macropores and water flow in soils; Water Resour. Res. 18(5) 1311-1325.

Bijayalaxmi D N and Yadava P S 2006 Seasonal dynamics in soil microbial biomass $\mathrm{C}, \mathrm{N}$ and $\mathrm{P}$ in a mixed-oak forest ecosystem of Manipur, North-east India; Applied Soil Ecology 31 220-227.

Borah M J and Kalita P K 1999 Development and evaluation of a macropore flow component for LEACHM; Transactions of the ASAE 42(1) 65-78.

Bosch J M and Hewlett J D 1982 A review of catchment experiments to determine the effect of vegetation changes on water yield and evapotranspiration; J. Hydrol. 55 $3-23$.

Bouma J and Dekker L W 1978 A case study on infiltration into dry clay soil, 1: Morphological observations; Geoderma 20 27-40.

Bouma J, Jongerius A and Schoonderbeek D 1979 Calculation of saturated hydraulic conductivity of some pedal clay soils using morphometric data; Soil Sci. Soc. Am. J. 43 261-264.

Bouma J and Wosten J H L 1979 Flow patterns during extended saturated flow in two undisturbed swelling clay soils with different macro structures; Soil Sci. Soc. Am. J. 43 16-22.

Bronstert A 1999 Capabilities and limitations of detailed hillslope hydrological modelling; Hydrol. Process. 13 $21-48$.

Bruijnzeel L A 1990 Hydrology of the moist tropical forests and effects of conversion: A state of knowledge review; HTP, UNESCO, Paris.

Buttle J M and McDonald D J 2000 Soil macroporosity and infiltration characteristics of a forest podzol; Hydrol. Process. 14(5) 831-848.

Calder I R 2000 Land use impacts on water resources, landwater linkages in rural watersheds; Electronic Workshop, Background Paper No. 1, FAO, Rome, Italy.

Cattle S R, Koppi A J and McBratney A B 1994 The effect of cultivation on the properties of a Rhodoxeralf from 
the wheat/sheep belt of New South Wales; Geoderma 63 $215-225$.

Chen S-K and Liu C W 2002 Analysis of water movement in paddy rice fields. (I) Experimental studies; J. Hydrol. $260206-215$.

de Rooij H and Stagnitti F 2000 Spatial variability of solute leaching: Experimental validation of a quantitative parameterization; Soil Sci. Soc. Am. J. 64 499-504.

Droogers P, Stein A, Bouma J and de Boer G 1998 Parameters for describing soil macroporosity derived from staining patterns; Geoderma 83 293-308.

Edwards K A 1977 Cultural practice and changes in catchment hydrology: A review of hydrological research techniques as aids to development planning in the humid tropics; In: Soil Conservation and Management in the Humid Tropics (eds) Greenland D J and Lal R (New York: Wiley) pp. 33-46, pp. 283.

Edwards W M, Shipitalo M J, Owens L B and Dick W A 1993 Factors affecting preferential flow of water and atrazine through Earthworm burrows under continuous no-till corn; J. Environ. Qual. 22 453-457.

Elçi A and Molz F J 2009 Identification of lateral macropore flow in a forested riparian wetland through numerical simulation of a subsurface tracer experiment; Water, Air $\mathcal{E}_{3}$ Soil Pollution 197(1-4) 149-164.

Fan Y and Bras R L 1998 Analytical solutions to hillslope subsurface storm flow and saturation overland flow; Water Resour. Res. 34(4) 921-927.

Flury M 1996 Experimental evidence of transport of pesticides through field soils - A review; J. Environ. Qual. 25 $25-45$.

Flury M, Flühler H, Jury W A and Leuenberger J 1994 Susceptibility of soils to preferential flow of water; Water Resour. Res. 30 1945-1954.

Forrer I, Kasteel R, Flurry M and Flühler H 1999 Longitudinal and lateral dispersion in an unsaturated field soil; Water Resour. Res. 35(10) 3049-3060.

Gafur A, Jensen J R, Borggaard O K and Petersen L 2003 Runoff and losses of soil and nutrients from small watersheds under shifting cultivation (Jhum) in Chittagong hill tracts of Bangladesh; J. Hydrol. 279 293-309.

German-Heins J and Flury M 2000 Sorption of Brilliant Blue FCF in soils affected by $\mathrm{pH}$ and ionic strength; Geoderma 97 87-101.

Germann P 1981 Untersuchungen über den Boden wasserhaushalt inn Einzugsgebiet Rietholzbach. Mitt. Versuchanst; Wasserbau Hydrol. Glaziologie ETH Zurich $\mathbf{5 1}$ 133.

Ghodrati M, Chendorain M and Chang Y J 1999 Characterization of macropore flow mechanism in soil by means of a split macropore column; Soil Sci. Soc. Am. J. 63 $1093-1101$.

Ghodrati M and Jury W A 1990 A field study using dyes to characterize preferential flow of water; Soil Sci. Soc. Am. J. 54(6) 1558-1563.

Goswami P C 1980 Problems of Jhum control; In: Tribal Economy in the North Eastern Region, Proceedings of a seminar on Tribal Economy organized by the Department of Economics in March, 1976. Sponsored by University Grants Commission, New Delhi, pp. 48-61.

Hoogmoed W D and Bouma J 1980 A simulation model for predicting infiltration into cracked clay soil; Soil Sci. Soc. Am. J. 44 458-461.

Jarvis N J 1998 Modelling the impact of preferential flow on non-point source pollution; In: Physical non-equilibrium in soils: Modeling and application (eds) Selim $\mathrm{H} \mathrm{H}$ and Ma L; (Chelsea, MI, U.S.A.: Ann Arbor Press) 195-221.

Jarvis N J, Jansson P-E, Dik P E and Messing I 1991 Modelling water and solute transport in macroporous soil. I. Model description and sensivity analysis; J. Soil Sci. 42 59-70.

Kar S and Das B S 2000 Soil water dynamics in rice eco-systems during rainy season; National Workshop on Rainwater and Groundwater Management for Rice Ecosystem, 25-26 September, 2000, IIT Kharagpur, India.

Lal R 1987 Tropical Ecology and Physical Edaphology; (New York: Wiley) pp. 732.

Larsson M H and Jarvis N J 1999 A dual porosity model to quantify macropore flow effects on nitrate leaching; J. Environ. Qual. 28 1298-1307.

Larsson M H and Jarvis N J 2000 Quantifying interactions between compound properties and macropore flow effects on pesticide leaching; Pest Management Science 56 133-141.

Li Y and Ghodrati M 1997 Preferential transport of solute through soil columns containing constructed macropores Soil Sci. Soc. Am. J. 61 1308-1317.

Ligon J T, Wilson T V, Allen J F and Singh U P 1977 Tracing vertical translocation of soil moisture; J. Hydraul. Div. Am. Soc. Civ. Eng. 103(HY 10) 1147-1158.

McDonnell J 1990 A rationale for old water discharge trough macropores in a steep, humid catchment; Water Resour. Res. 26(11) 2821-2832.

Merril C R 1990 Gel-staining techniques, In: Guide to protein purification methods in enzymology (ed.) Deutscher M P, Academic Press Inc., Volume 182.

Mishra S K, Sarkar R, Dutta S and Panigrahy S 2008 A physically based hydrological model for paddy agriculture dominated hilly watersheds in tropical region; J. Hydrol. 357 389-404.

Mooney S J and Morris C 2008 A morphological approach to understanding preferential flow using image analysis with dye tracers and X-ray computed tomography; Catena $\mathbf{7 3}$ 204-211.

Morris C and Mooney S J 2004 A high-resolution system for the quantification of preferential flow in undisturbed soil using observations of tracers; Geoderma 118 $133-143$

Natsch A, Keel Ch, Troxler J, Zala M, von Albertini N and Défago G 1996 Importance of preferential flow and soil management in vertical transport of a biocontrol strain of pseudomonas fluorescens in structured field soil; Appl. Environ. Microbiol. 62(1) 33-40.

Návar J, Turton D J and Miller E L 1995 Estimating macropore and matrix flow using the hydrograph separation procedure in an experimental forest plot; Hydrol. Process. 9(7) 743-753.

Negi G C S 2001 The need for micro-scale and mesoscale hydrological research in the Himalayan mountains; Environ. Conserv. 28 95-98.

Öhrström P, Persson M, Albergel J, Zante P, Nasri S, Berndtsson R and Olsson J 2002 Field-scale variation of preferential flow as indicated from dye coverage; J. Hydrol. 257 164-173.

Olsen P A and Børresen T 1997 Measuring differences in soil properties in soils with different cultivation practices using computer tomography; Soil $\mathscr{E}$ Tillage Research 44(1-2) 1-12.

Omoti U and Wild A 1979 Use of fluorescent dyes to mark the pathways of solute movement through soils under leaching conditions. 2. Field experiments; Soil Sci. 128(2) 98-104.

Pagliai M, Vignozzi N and Pellegrini S 2004 Soil structure and the effect of management practices; Soil \& Tillage Research 79 131-143.

Paulo A M, Pereira L A, Teixeira J L and Pereira L S 1995 Modelling paddy rice irrigation; In: Crop-Water simulation models in practice (eds) Pereira L S, 
Van den Broek B J, Kabat P and Allen R G, Wageningen Pers, Netherlands, pp. 287-302.

Perillo C A, Gupta S C, Nater E A and Moncrief J F 1999 Prevalence and initiation of preferential flow paths in a sandy loam argillic horizon; Geoderma 89 307-331.

Quisenberry V L and Phillips R E 1976 Percolation of surface-applied water in the field; Soil Sci. Soc. Am. J. 40 484-489.

Rajot J L, Léonard J and Perrier E 2004 Biological macropores effect on runoff and infiltration: A combined experimental and modelling approach; Agriculture, Ecosystems \& Environment 104(2) 277-285.

Rezzoug A, Schumann A, Chifflard P and Zepp H 2005 Field measurement of soil moisture dynamics and numerical simulation using the kinematic wave approximation; $A d v$. Water Resour. 28 917-926.

Sanchez P A and Hailu M (eds) 1996 Alternatives to slashand-burn agriculture; Agric. Ecosyst. Environ. 58 1-86.

Sarkar R and Dutta S 2009 An experimental and modelling investigation of macropore dominated subsurface stormflow in vegetated hillslopes of northeast India, In: New approaches to hydrological prediction in data-sparse regions (eds) Yilmaz K K, Yucel I, Gupta H V, Wagener T, Yang D, Savenije H, Neale C, Kunstmann H and Pomeroy J, IAHS Publication 333 145-152.

Sarkar R, Dutta S and Panigrahy S 2008a Characterizing overland flow on a preferential infiltration dominated hillslope: Case study; J. Hydrol. Engg. 13(7) 563-569.

Sarkar R, Dutta S and Panigrahy S 2008b Effect of scale on infiltration in a macropore dominated hillslope; Curr. Sci. 94(4) 490-494.

Sastry G and Narayanan D 1986 Hydrological response of small watersheds to different land use in Doon Valley; Indian J. Agri. Sci. 56 194-197.

Scanlan C and Hinz C 2007 A conceptual model to quantify plant root induced changes in soil hydraulic conductivity and water retention; International Annual Meetings of ASA-CSSA-SSSA, 4-8 November, 2007, New Orleance, Louisiana.

Seethapathi P V, Dutta D and Siva Kumar R (eds) 2008 Hydrology of small watersheds; The Energy and Resources Institute (TERI), New Delhi.

Sharma P N 1992 Status and needs for forest watershed management in Vietnam; Transactions of the American Society of Agricultural Engineers 8(4) 461-469.

Singh V P, Sharma N and Ojha C S P 2004 The Brahmaputra Basin Water Resources (Netherlands: Kluwer Academic Publishers).

Shipitalo M J and Edwards W M 1996 Effects of initial water content on macropore/matrix flow and transport of surface-applied chemicals; J. Environ. Qual. $\mathbf{2 5}$ 662-670.

Shipitalo M J, Edwards W M, Dick W A and Owens L B 1990 Initial storm effects on macropore transport of surface applied chemicals in no-till soil; Soil Sci. Soc. Am. J. 54 1530-1536.

Sidle R C, Tsuboyama Y, Noguchi S, Hosoda I, Fujieda M and Shimizu T 2000 Storm-flow generation in steep forested headwaters: A linked hydrogeomorphic paradigm; Hydrol. Process. 14 369-385.

Sloan P G, Moore I D, Coltharp G B and Eigel J D 1983 Modeling surface and subsurface stormflow on steeplysloping forested watersheds; Research Report No. 142, Water Resour. Res. Inst., Univ. of Kentucky, Lexington, Kentucky, pp. 131.

Smettem K R J, Chittleborough D J, Richards B G and Leaney F W 1991 The influence of macropores on runoff generation from a hillslope soil with a contrasting textural class; J. Hydrol. 122 235-252.
Soja R and Starkel L 2007 Extreme rainfalls in Eastern Himalaya and southern slope of Meghalaya Plateau and their geomorphologic impacts; Geomorphology 84 $170-180$.

Stracey P D 1967 A note on Nagaland; Journal of the Bombay Natural History Society 64 440-446.

Ticehurst J L, Cresswell H P and Jakeman A J 2003 Using a physically based model to conduct a sensitivity analysis of subsurface lateral flow in south-east Australia; Environmental Modelling $\&$ Software 18 729-740.

Troch P, van Loon E and Hilberts A 2002 Analytical solutions to a hillslope-storage kinematic wave equation for subsurface flow; Adv. Water Resour. 25 637-649.

Tuan V V 1993 Evaluation of the Impact of deforestation to inflow regime of the Hoa Binh Reservoir in Vietnam; In: Hydrology of Warm Humid Regions, Proceedings of the Yokahama Symposium, July 1993. IAHS Publication 216 135-138.

Uchida T, Meerveld I T and McDonnell J J 2005 The role of lateral pipe flow in hillslope runoff response: An intercomparison of non-linear hillslope response; J. Hydrol. 311 117-133.

Vadivelu S, Sen T K, Bhaskar B P, Baruah U, Sarkar D, Maji A K and Gajbhiye K S 2004 Soil series of Assam, Technical Bulletin, NBSS Publ. 101, National Bureau of Soil Survey and Land Use Planning, Indian Council of Agricultural Research, India.

van Stiphout T P J, van Lanen H A J, Boersma O H and Bouma J 1987 The effect of bypass flow and internal catchment of rain on the water regime in a clay loam grassland soil; J. Hydrol. 95 1-11.

Velayutham M, Mandal D K, Mandal C and Sehgal J 1999 Agro-Ecological Subregions of India for Planning and Development, Publ. No. 35, National Bureau of Soil Survey and Land Use Planning, Indian Council of Agricultural Research, India, 372p.

Wahl N A, Buczko U, Bens O and Hüttl R F 2003 Infiltration capacity and macroporosity of a silty-loamy soil under different tillage systems; Geophys. Res. Abstr. 5 05326 .

Wang K, Zhang R and Yasuda H 2006 Characterizing heterogeneity of soil water flow by dye infiltration experiments; J. Hydrol. 328 559-571.

Weibel E R 1979 Stereological methods, Vol. 1, Practical methods for biological morphometry (London: Academic Press).

Weiler M 2001 Mechanisms controlling macropore flow during infiltration: Dye tracer experiments and simulations; Ph.D Thesis, Swiss Federal Institute of Technology, Zurich, Switzerland.

Weiler M 2005 An infiltration model based on flow variability in soil macropores: Development, sensitivity analysis and applications; J. Hydrol. 310 294-315.

Weiler M and Flühler H 2004 Inferring flow types from dye patterns in macroporous soils; Geoderma 120(1-2) 137-153.

Weiler M and McDonnell J 2004 Virtual experiments: A new approach for improving process conceptualization in hillslope hydrology; J. Hydrol. 285(1-4) 3-18.

Weiler M and Naef F 2003 An experimental tracer study of the role of macropores in infiltration in grassland soils; Hydrol. Process. 17(2) 477-493.

World Bank 2007 Development and growth in northeast India: The natural resources, water and environment nexus; Strategy Report of South Asia Region, Socially Sustainable Development Department, Environment Unit, Report No. 36397-IN, pp. 8. 
Yu P, Wang Y and Kuo C 2003 Effect of land-use change on runoff response in the ungauged Ta-Chou basin, Taiwan; In: Erosion Prediction in Ungauged Basins: Integrating Methods and Techniques; IAHS Publication 279 162-170.

Zhao W, Fu B, Chen L, Zhang Q and Zhang Y 2004 Effects of land-use pattern change on rainfall-runoff and runoffsediment relations: A case study in Zichang watershed of the Loess Plateau of China; J. Environ. Sci. 16(3) 436-442.

Ziegler A D, Giambelluca $\mathrm{T}$ W, Tran L T, Vana $\mathrm{T} T$, Nullet M A, Fox J, Vien T D, Pinthong J, Maxwell J F and Evett S 2004 Hydrological consequences of landscape fragmentation in mountainous northern Vietnam: Evidence of accelerated overland flow generation; J. Hydrol. 287(1-4) 124-146.

MS received 24 January 2009; revised 5 June 2010; accepted 7 June 2010 